\author{
Military Technical College \\ Kobry El-Kobba \\ Cairo, Egypt
}

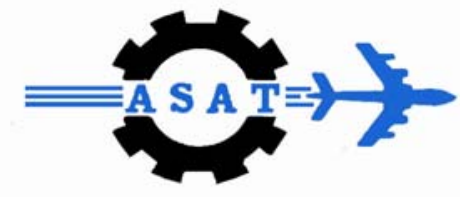

12-th International Conference

on

Aerospace Sciences \&

Aviation Technology

\title{
IDENTIFICATION OF DAMAGE IN PLATE-LIKE STRUCTURES USING TWO STAGE ALGORITHM COMBINES NON- MODEL BASED AND MODEL BASED TECHNIQUES
}

\author{
Abdelkhalik, M. *, Amin, M. S. ** and Zidan, M. K. ***
}

\begin{abstract}
The regular structural integrity monitoring of major engineering structures such as space structures, orbiting spacecrafts, and civil infrastructures have become an urgent necessity to prevent potential catastrophic failures. The evolution of Vibration Based Damage Identification methods (VBDI) introduced an alternative techniques to the conventional methods. These methods relate changes in the vibration signature (natural frequencies and mode shapes) to changes in structural physical parameters (mass and stiffness) and thus is used to identify damage. The present research focus on developing a combined algorithm includes a model-based method (optimal matrix update) and a Non model-based method (frequency response functions difference), to enhance the reliability of the VBDI techniques. The algorithm presented robust sequential scheme of VBDI techniques and has proven a reasonable success when tested through numerical simulation on a large complex space frame. Since, the FEM of the monitored structure considered as a major constitute of the identification procedure, in the present paper, the ability of the proposed combined algorithm to identify damage in plate-like structure is investigated. A numerical simulation is carried out by introducing several damage scenarios to steel plate and predictions were compared to the known damage. Regardless the assumptions made in the FEM and the introduced simulated random errors introduced at different steps in the algorithm procedures, the algorithm is found to be reliable in identifying damage in plate-like structures.
\end{abstract}

\section{KEYWORDS}

Vibration-based damage detection, structural health monitoring, identification of damage in plate-like structures, frequency response function, optimal matrix update, optimization.

\footnotetext{
* Msc, Civil Eng. Department, Military Technical College, Egyptian Armed Forces, Egypt.

** Ph.D, Civil Eng. Department, Military Technical College, Egyptian Armed Forces, Egypt.

*** Professor, Civil Eng. Department, Faculty of Engineering, Ain Shams University, Cairo, Egypt.
} 


\title{
NOMENCLATURE
}

\author{
K $\quad$ System stiffness matrix. \\ M System mass matrix. \\ סK Perturbations to the system stiffness matrix. \\ $\phi_{i} \quad$ The $i^{\text {th }}$ mass-orthonormal mode shape \\ $\omega_{i} \quad$ The $i^{\text {th }}$ natural frequency. \\ $\lambda_{1} \quad$ The $\mathrm{i}^{\text {th }}$ eigenvalue (squared frequency). \\ $\delta \phi_{\mathrm{i}} \quad$ The change in the $\mathrm{i}^{\text {th }}$ mode shape. \\ $\delta \lambda_{1} \quad$ The change in the $i^{\text {th }}$ eigenvalue. \\ $\phi_{\text {id }} \quad$ The $i^{\text {th }}$ mode shape of damaged structure \\ FRF Frequency response function \\ NDE Non destructive evaluation \\ SHM Structural health monitoring \\ VBDI Vibration based damage identification
}

\section{INTRODUCTION}

In recent decades, the damage detection at the earliest possible stage has become an important issue in almost all areas ranging from aerospace, aeronautical, mechanical and civil engineering. Most currently used damage identification methods are visual or localized experimental such as acoustic, ultrasonic, magnetic, radiography or thermal field methods. However, these methods are proven to be impractical in monitoring complex structures. This is so because, these methods require that the vicinity of damage is known in advance and that the portion of the structure being inspected is readily accessible. Moreover they require structures to be temporarily withdrawn from service. An effective alternative in Structural Health Monitoring (SHM) is to recognize the fact that the modal vibration test data (structural natural frequencies and mode shapes) characterize the state of the structure. Since damage generally causes changes in the mechanical properties of the structural system, such as stiffness, the problem of locating a damaged site on structure can be equated to locating regions where stiffness or load carrying capacity has been reduced by a measurable amount. If the resonant frequencies and mode shapes are measured before and after damage, it is possible to solve an inverse problem to determine the changes in system matrices. These changes thus provide an indication of the location and magnitude of the damage.

The optimal matrix update method is one of the identification algorithms which have been used in VBDI techniques. Optimal update identification is an approach to produce, through the solution of a constrained non-linear optimization problem, update property matrices (mass, stiffness and damping) that will yield a close match between the analytical and measured modal responses. It is categorized as modelbased damage identification algorithm, which depends on a prior Finite Element Model (FEM) of the healthy structure to be used as a base line. It can be used to identify the damage location and severity. However, sometimes the optimizer may lead to false predictions especially when a large number of design variables is 
included in the optimization process. In order to overcome this defect, Amin et al. [1] combined an optimal matrix update technique with FRF differences technique, which is independent on a FEM of the monitored structure (i.e. non-model-based algorithm). The FRF differences technique is used to identify the damaged region to minimize the number of the suspected damaged elements and hence reducing the number of design variables included in the optimization process. It is based on the analysis of experimentally acquired Frequency Response Functions (FRFs) and consists of a comparison of the FRFs of the healthy structure which are assumed as reference and the FRFs collected at different times.

Although over the past 30 years detecting damage in a structure from changes in global dynamic parameters has received considerable attention from civil, aerospace, and mechanical engineering communities, there have been very few theoretical studies on the identification of damage within two-dimensional continua such as the plates. Cawley and Adams [2] were the first to locate the defects within a rectangular plate by using natural frequency changes only. However, frequency information has been shown to be insufficient for identifying damage in large structures due to the insensitivity of frequency changes to small damage [3]. Araujo dos Santos et al. [4] used both natural frequencies and vibration modes to detect damage within a laminated rectangular plate. However, their method was not practical for a real structure because the method requires a significant number of frequencies and corresponding mode shapes to yield reliable solutions, which is not usually measurable from real structures. Chen and Bicanic [5] introduced a method in which the incomplete natural frequencies and vibration modes can be used to detect damage within a cantilever plate. Later on, Khadem and Rezaee [6] developed an analytical approach in which the changes in natural frequencies are used for obtaining the location and depth of a crack on the in-plane loaded plate. Recently, Lee and Shin [7] developed a method that can locate and quantify damage in a plate structure. While their iterative procedure seems practicable, their approach needs harmonic excitation that restricts the applicability to real structures [8]. In the present paper, the ability of the aforementioned two stage algorithm, which developed by Amin et al. [1], to identify damage in a free-free steel plate is tested via a series of numerical simulations. In the following sections, the theoretical background of the two stage algorithm, a description of the tested plate and a discussion of results and conclusions are presented.

\section{THEORETICAL BACKGROUND}

\section{Optimal matrix update method}

Although the optimal matrix update algorithms can be used to update mass, damping and stiffness matrices, stiffness matrix updating has been the most widely used method for damage identification. This is so because damage is most likely to affect the stiffness matrix. For both FEM updating and damage identification, the stiffness matrix is considered the most important candidate for updating based on the measured modal data. A brief description to the optimal matrix update technique used in the two stage algorithm is presented. More detailed description can be found in Amin [9]. 
The eigenvalue equation of an undamped $n$-degree of freedom system is

$$
\left(\mathbf{K}-\boldsymbol{\lambda}_{\mathrm{i}} \mathbf{M}\right) \phi_{\mathrm{i}}=0
$$

Where $\mathbf{M}$ is an nxn mass matrix, $\mathbf{K}$ is an nxn stiffness matrix, $\lambda_{i}$ is the square of the $\mathrm{i}^{\text {th }}$ natural frequency, $\omega_{\mathrm{i}}$, and $\phi_{\mathrm{i}}$ is the corresponding mode shape of the system. Assuming that damage in the original structure does not cause any change in the system mass matrix and causes a change in the stiffness matrix by an amount $\delta \mathbf{K}$, this change leads to change $\delta \lambda_{\mathrm{i}}$ in the $\mathrm{i}^{\text {th }}$ eigenvalue and $\delta \phi_{\mathrm{i}}$ in the $\mathrm{i}^{\text {th }}$ eigenvector. The eigenvalue equation of the damaged structure should be

$$
\left[\mathrm{K}+\delta \mathrm{K}-\left(\boldsymbol{\lambda}_{\mathrm{i}}+\delta \boldsymbol{\Lambda}_{\mathrm{i}}\right) \mathrm{M}\right]\left[\phi_{\mathrm{i}}+\delta \phi_{\mathrm{i}}\right]=0
$$

On multiplying Equation (2) by $\phi_{\mathrm{i}}^{\top}$ and using Equation (1) and noting that $\delta \phi_{\mathrm{i}}=\phi_{\mathrm{id}}-\phi_{\mathrm{i}}$, where $\phi_{\mathrm{id}}$ is the $\mathrm{i}^{\text {th }}$ mode shape of the damaged structure, we can get

$$
\phi_{\mathrm{i}}^{\top} \delta \mathrm{K} \phi_{\mathrm{id}}=\delta \boldsymbol{\Lambda}_{\mathrm{i}} \phi_{\mathrm{i}}^{\top} \mathbf{M} \phi_{\mathrm{id}}
$$

The change in the stiffness matrix $\boldsymbol{\delta} K$ can be expressed as the weighted sum of the stiffness matrices of the damaged elements. The weighting factors, which are the unknown in the problem, define the severity of damage in the affected elements. If $\mathbf{K}_{\mathbf{j}}^{\mathbf{e}}$ is the contribution of the $\mathrm{j}^{\text {th }}$ element to the global stiffness matrix of the structure, $\mathrm{n}_{\mathrm{e}}$ is the number of elements in the n-DOFs structure and $\delta \mathbf{K}_{\mathbf{j}}$ is the proportional change in the stiffness of element $\mathrm{j}$. consequently, $\delta \mathrm{K}$ can be written as

$$
\delta \mathbf{K}=\sum_{\mathbf{j}=1}^{\mathbf{n}_{\mathrm{e}}} \delta \mathbf{K}_{\mathbf{j}} \mathbf{K}_{\mathbf{j}}^{\mathbf{e}}
$$

Substitution of equation (4) into equation (3) gives a system of simultaneous equations

$$
\sum_{\mathrm{j}=1}^{\mathrm{n}_{\mathrm{e}}} \phi_{\mathrm{i}}^{\mathrm{T}} \mathbf{K}_{\mathrm{j}}^{\mathrm{e}} \phi_{\mathrm{id}} \delta \mathrm{K}_{\mathrm{j}}=\delta \boldsymbol{\Lambda}_{\mathrm{i}} \phi_{\mathrm{i}}^{\mathrm{T}} \mathbf{M} \phi_{\mathrm{id}} \quad \mathrm{i}=1,2, \ldots, \mathrm{m}
$$

Where $\mathrm{m}$ is the number of modes used in the identification process. The system presented by equation (5) can be simplified to the form

$$
\mathrm{D} \delta \mathrm{K}=\delta \lambda
$$

Where $\mathbf{D}$ is an mxne matrix of elements $\mathbf{d}_{\mathrm{ij}}=\phi_{\mathrm{i}}{ }^{\top} \mathbf{K}_{\mathrm{j}}^{\mathrm{e}} \phi_{\mathrm{id}} / \phi_{\mathrm{i}}^{\top} \mathbf{M} \phi_{\mathrm{id}}, \delta \mathrm{K}$ is the $\mathrm{n}_{\mathrm{e}}$ vector of unknown changes in the stiffness $\delta K_{\mathrm{j}}$, and $\delta \lambda$ is the $\mathrm{m}$ vector of changes in the 
eigenvalues $\delta \boldsymbol{\lambda}_{\mathrm{i}}$. In practice not all the structure modes can be measured, because reliable measurements can be obtained for only the lower modes. Consequently, the system of simultaneous equations in (5) is Indeterminate. A unique solution can be obtained by placing equation (5) as a constraint on an objective function through the solution of optimization problem. The objective function used in the present work is to minimize the square of the Frobenius norm of perturbations to the stiffness matrix. Minimization of the squared norm of change in the stiffness $\boldsymbol{\delta} K$ matrix can be expressed by

$$
\min \sum_{i=1}^{n} \sum_{j=1}^{n} \sum_{r=1}^{n_{e}} \sum_{s=1}^{n_{e}} K_{r}^{e}(i, j) K_{s}^{e}(i, j) \delta K_{r} \delta K_{s}
$$

Where $\mathbf{K}_{r}^{\mathbf{e}}(\mathbf{i}, \mathbf{j})$ is the $\mathrm{ij}^{\text {th }}$ coefficient of matrix $\mathbf{K}_{\mathbf{r}}^{\mathbf{e}}$. Equation (7) is an expanded form of the quadratic programming problem defined by

\section{$\min \delta K^{\top} \mathbf{Q} \delta K$}

Where $\mathbf{q}_{\mathbf{r s}}=\sum_{\mathbf{i}=1}^{\mathrm{n}} \sum_{\mathbf{j}=1}^{\mathrm{n}} \mathbf{K}_{\mathbf{r}}^{\mathbf{e}}(\mathbf{i}, \mathbf{j}) \mathbf{K}_{\mathbf{s}}^{\mathbf{e}}(\mathbf{i}, \mathbf{j})$ and $\delta \mathbf{K}$ is the vector of the unknown damage parameters. Considering that damage cannot result in a positive change in elemental stiffness matrix, an additional inequality constraint can be placed on the stiffness changes

$$
-1 \leq \boldsymbol{\delta} \mathbf{K} \leq 0
$$

The problem defined above is a nonlinear optimization problem. In the present work, MATLAB codes were developed to prepare the different parameters for the non linear optimization problem, which is solved using the optimization toolbox in computer software MATLAB.

\section{FRF DIFFERENCES TECHNIQUE}

VBDI methods are categorized according to various criteria such as the level of damage detection provided, model-based versus non-model-based relations, and linear versus nonlinear approaches. Non-model-based methods determine the presence of damage in a structure and at most identify the location of damage. Another classification system divides these methods into: Modal-databased Methods, and FRF-databased Methods. FRF-databased Methods have several advantages over the Modal-databased Methods. The FRF-data will not be contaminated by modal extraction errors because the FRF-data are directly measured test data. Furthermore, the FRF-data can provide much more damage information in a desired frequency range than modal data because modal data are extracted mainly from a very limited number of FRF data around resonance [10]. Thus, motivated from the advantages of FRF-data, in the present study a non-model-based Damage Detection Index (DDI) that interprets the differences between the FRFs measured for the healthy structure and the FRFs of the damaged structure is used to detect the 
damaged region. Amin et al [1] developed a modified DDI to localize damage in an eight-bay space frame. The DDI is given by the following expression:

$$
D D I=\frac{\sum_{i=1}^{n}\left|F I_{i}-F D_{i}\right|}{\sum_{i=1}^{n} F I_{i}} \times 100
$$

Where Fli and FDi are the amplitude of the FRFs of the healthy and damaged structures respectively, $\mathrm{n}$ is the number of FRF points in the sweep range. This nonmodel-based technique warrants simplicity and speed in data acquisition and elaboration since it is free from modal analysis, and is able to perform a real-time monitoring of in-service structures. FRFs of the healthy and damaged structures were analytically created for the numerical simulation purposes. The FRFs are created using the following equation:

$$
\mathbf{X}_{0}=\alpha(\omega) \mathbf{F}_{0}
$$

Where $\mathbf{X}_{0}$ is the response vector, $F_{0}$ is the excitation vector and $\alpha(\omega)$ is called the frequency response function (FRF), and it relates the output per unit of input at each frequency $\boldsymbol{\omega}$. This equation is derived from the equation of motion governing the forced vibration of an undamped multi-degree of freedom system. The theoretical basis of this method can be found in Maia et al [11].

\section{Description of the Test Plate}

The numerical simulation has been applied to a simple free-free plate has a dimensions of $3 \times 3 \times 0.02 \mathrm{~m}$. The plate is assumed to be made of steel with young's modulus, $E=1.999 \times 10^{11} \mathrm{~N} / \mathrm{m} 2$, possion's ratio, $\mathrm{V}=0.3$ and mass per unit volume, $\rho=7849.05 \mathrm{Kg} / \mathrm{m3}$. Fig.1 illustrates the geometric configuration of the plate.

\section{Finite Element Model}

The FEM of the steel plate was formulated using plate bending element, which carries only lateral loads in bending, each node has three DOFs and the model has a total of 147 DOFs. The DOFs at each node are: lateral displacement of the neutral plane in the direction of z-axis denoted by $\mathbf{w}$; slope in the $\mathrm{x}$ direction denoted by $\partial \mathrm{w} / \partial \mathrm{x}$ or $\mathrm{w}_{\mathrm{x}}$ and slope in the $\mathrm{y}$ direction denoted by $\partial \mathrm{w} / \partial \mathbf{y}$ or $\mathbf{w}_{\mathrm{y}}$. Since the thickness of the plate is very small compared with its other two dimensions, it can be categorized as thin plate. Consequently, thin plate finite element, in which Kirchhoff theory is applicable, was used to model the plate. The stiffness and consistent mass matrix of this element can be found in Yang [12]. The plate is divided into 36 elements $(6 \times 6)$ with total number of nodes $=49$. Each element is a four-node rectangular element with dimensions $0.5 \times 0.5 \times 0.02 \mathrm{~m}$. Fig. 2 shows the discretization of the plate and displays the elements connectivity. 
In a real modal test it is often impractical to measure the response at all of the DOFs included in a FEM. Consequently, there is a desire to match the size of the experimentally measured DOFs with the analytical ones and to bring them both to the same size. This can be achieved either by reducing the analytical model down to the order determined by the number of measured DOFs, or by expanding the experimental model so that it is described by the same number of DOFs as the complete analytical model. Several model reduction techniques have been proposed, however, most of these techniques affect the dynamic character contained in the original full analytical model. Generally, the estimated frequencies in the reduced model are higher than those of the original model [13]. The System Equivalent Reduction Expansion Process (SEREP) by the nature of its formulation retains all of the dynamics of the full model in the reduced state for the modes selected in the reduction process and by definition contains no approximation [13]. Consequently this technique is used in the present work.

\section{Damage Scenarios}

The developed algorithm consists mainly of two steps: (1) determining the damaged region via a non-model-based technique that is the FRF differences technique, (2) identifying the damage location and extent via a model-based technique that is the optimal matrix update. The algorithm is executed through several steps, which combine various mathematical procedures. These steps are summarized in the flow chart illustrated in Fig. 3 and explained in [14]. Numerical simulation tested different damage scenarios at single and multiple sites. To achieve this goal two damages severities are studied: $90 \%$ reduction in the element stiffness, which is considered as severe damage and $60 \%$ reduction in the element stiffness, which is considered as light damage. The damage cases are divided into three groups: The first group (G1) includes only severe damage cases, the second group (G2) includes mixed damage cases in which some of the elements are severely damaged and the others are lightly damaged, and the third group (G3) includes light damage cases. Sample of the numerical simulation results is presented here in. Table 1. displays this sample. Results of more damage scenarios can be found in [14].

In practice, the modal database is usually being corrupted by measurement, modal extraction or modeling errors. In order to simulate the effect of these errors, random errors were applied to the modal parameters and to the FRFs data of the healthy and damaged structures in all the damage scenarios. A vector of random errors varying between $(0 \%-10 \%)$ of the exact values is used for the mode shape vector and FRFs data. For the frequencies, a vector of random errors varying between $(0 \%-2$ $\%)$ of the exact values is used. The random vectors are generated via the RAND generator in MATLAB. 


\section{RESULTS AND CONCLUSIONS}

Results of some of the damaged cases studied during the computer simulation are discussed here. Tables ( $2 \& 3$ ) illustrate the changes in frequencies for each of the damage cases. Samples of FRFs before and after damage for each damage group are shown in Fig.4 to Fig.6. Damage identification results for each damage case are shown in Fig. 7 to Fig. 14. These results are based on incomplete mode shapes that were defined along only 70 DOFs. For all damage cases, Figures labeled (a) show the damage identification results when all the 36 elements are included as design variables in the optimization problem. Figures labeled (b) show the DDI values due to excitation at (34-Z). Examining the DDIs figures for each damage case showed that for all the damage scenarios, the implementation of FRF difference technique has the influence in isolating the damaged region precisely. As a result, all the candidate damaged elements within the damage region were determined even when a higher number of elements were damaged. Figures labeled (c) show the damage identification results when only a limited number of elements, resulting from damaged region isolation, is included in the optimization problem.

Figures labeled (a) demonstrate that in case of including all the 36 elements in the optimization process, the model-based technique identified the damage location and extent with acceptable accuracy in most damage cases. However in all the identification results, false elements were identified as damaged ones and the severity of damage was not exactly determined. This is dependant on the strain energy contribution of the damaged elements in the identification modes. As the strain energy contribution in the identification modes increases as the better identification results obtained. Figures labeled (c) demonstrate that after identifying the damaged region, and hence reducing the number of suspected elements included in the optimization problem, the number of false predicted elements is significantly cleared and the identification of damage severity is improved in most cases.

The inclusion of the FRF differences technique as the first step in the proposed algorithm assured the identification of the damaged region. This success can be attributed to the advantages of the technique discussed earlier. Consequently, the number of suspected candidate elements is decrease to be included in the formulation of the second identification step. The implementation of the optimal matrix update method in the second step easily usually resulted in an improved and refined damage identification for the exact location with close values for the damage severity. The algorithm procedures proved to improve the performance with respect to the optimal matrix update and leads to better results than those obtained when all the elements are included in the optimization problem. In general, it is found that in the presence of simulated random errors, the developed two stage algorithm is reliable in identifying damage in plate-like structures. 


\section{REFERENCES}

[1] Amin, M. S., Abdelkhlik, M. and Zidan, M. K., " Structural Health Monitoring using Two Stage Algorithm Combines Non Model Based and Model Based Techniques" proceedings of the $6^{\text {th }}$ ICCAE Conf., pp. 102-122, May (2006)

[2] Cawley, P. and Adams, RD., "The location of defects in structures from measurements of natural frequencies". Journal of Strain Analysis, vol. 14(2), pp. 49-57, (1979).

[3] Pandey, A. K., Biswas, M. and Samman, M. M. "Damage detection from changes in curvature mode shapes." Journal of Sound and Vibration, 145(2): pp. 321-332, (1991).

[4] Araujo dos Santos, J. V., Mota Soares, C. M., Mota Soares, C. A. and Pina, H. L. G., "Damage identification: a numerical model". AIAA, vol. 1508, pp. 244952, (1999).

[5] Chen, H. P. and Bicanic, N., "Assessment of damage in continuum structures based on incomplete modal information". Computers and Structures, vol. 74, pp. 559-570, (2000).

[6] Khadem, S. E. and Rezaee, M., "An analytical approach for obtaining the location and depth of an all-over part-through crack on externally in-plane loaded rectangular plate using vibration analysis". Journal of Sound and Vibration, vol. 230(2), pp. 291-308, (2000).

[7] Lee, U. and Shin, J., "A structural damage identification method for plate structures". Engineering Structures, vol. 24, pp. 1177-1188, (2002).

[8] Choi, S., Park, S., Yoon, S. and Stubbs, N.," Nondestructive damage identification in plate structures using changes in modal compliance". NDT \& $\mathrm{E}$ International, pp. 1-12, (2005).

[9] Amin, M. S., "An Integrated Vibration-Based Structural Health Monitoring System", Ph. D dissertation Carleton University, Ottawa, Canada, (2002).

[10] Wang, Z., Lin, R.M. and Lim, M.K. "Structural Damage Detection Using Measured FRF Data", Computer Methods in Applied Mechanics and Engineering, vol. 147, pp. 187-197, (1997).

[11] Maia, N. M. M., Silva, J. M. N., He, J., Lieven, N. A. J., Lin, R. M., Skingle, G. W., to, W-M, and Urguira, A. P. V., "Theoretical and Experimental Modal Analysis", Research Studies Press, Taunton, Somerset, England, (1997).

[12] Yang T. Y., "Finite Element Structural Analysis", Prentice-Hall, Englewood Cliffs, pp. 399-428, (1986).

[13] O'Callahan, J.C., Avitabile, P. and Riemer, R., "System Equivalent Reduction Expansion Process (SEREP)", proceeding of the $7^{\text {th }}$ International Modal Analysis Conference, IMAC, pp. 29-37, February (1989).

[14] Abdelkhalik, M., "Defects Identification of Structural and Mechanical Systems from Changes in their Vibration Characteristics", M. Sc. dissertation, Military Technical College, Cairo, Egypt, (2007). 
Table 1: Damage scenarios for different groups

\begin{tabular}{|c|c|c|c|c|}
\hline $\begin{array}{c}\text { Damage } \\
\text { Group }\end{array}$ & $\begin{array}{l}\text { Damage } \\
\text { Case ID }\end{array}$ & $\begin{array}{l}\text { Damaged } \\
\text { Elements }\end{array}$ & $\begin{array}{c}\text { Elements } \\
\text { Connectivity }\end{array}$ & $\begin{array}{c}\text { Damage } \\
\text { Severity \% }\end{array}$ \\
\hline \multirow{3}{*}{$\begin{array}{c}\text { G1 } \\
\text { (Severe) }\end{array}$} & DS1 & 3 & 3-4-10-11 & 90 \\
\hline & DS2 & $\begin{array}{l}22 \\
23\end{array}$ & $\begin{array}{l}25-26-32-33 \\
26-27-33-34\end{array}$ & $\begin{array}{l}90 \\
90\end{array}$ \\
\hline & DS3 & $\begin{array}{l}16 \\
21 \\
22\end{array}$ & $\begin{array}{l}18-19-25-26 \\
24-25-31-32 \\
25-26-32-33\end{array}$ & $\begin{array}{l}90 \\
90 \\
90\end{array}$ \\
\hline \multirow[b]{2}{*}{$\begin{array}{c}\text { G2 } \\
\text { (Mixed) }\end{array}$} & DM1 & $\begin{array}{l}18 \\
24\end{array}$ & $\begin{array}{l}20-21-27-28 \\
27-28-34-35\end{array}$ & $\begin{array}{l}90 \\
60\end{array}$ \\
\hline & DM2 & $\begin{array}{c}8 \\
9 \\
10\end{array}$ & $\begin{array}{c}9-10-16-17 \\
10-11-17-18 \\
11-12-18-19\end{array}$ & $\begin{array}{l}90 \\
90 \\
60\end{array}$ \\
\hline \multirow{3}{*}{$\begin{array}{c}\text { G3 } \\
\text { (Light) }\end{array}$} & DL1 & 16 & $18-19-25-26$ & 60 \\
\hline & DL2 & $\begin{array}{l}15 \\
21\end{array}$ & $\begin{array}{l}17-18-24-25 \\
24-25-31-32\end{array}$ & $\begin{array}{l}60 \\
60\end{array}$ \\
\hline & DL3 & $\begin{array}{l}15 \\
16 \\
21 \\
\end{array}$ & $\begin{array}{l}17-18-24-25 \\
18-19-25-26 \\
24-25-31-32 \\
\end{array}$ & $\begin{array}{l}60 \\
60 \\
60 \\
\end{array}$ \\
\hline
\end{tabular}

Table 2: Changes in frequencies caused by damage in severe and mixed cases

\begin{tabular}{|c|r|r|r|r|r|r|r|r|r|r|}
\hline \multirow{2}{*}{$\begin{array}{c}\omega_{u} \\
(\mathrm{HZ})\end{array}$} & \multicolumn{4}{|c|}{ G1 (Sever Damage) } & \multicolumn{3}{|c|}{ G2 (Mixed Damage) } \\
\cline { 2 - 12 } & \multicolumn{2}{|c|}{ DS1 } & \multicolumn{2}{|c|}{ DS2 } & \multicolumn{2}{c|}{ DS3 } & \multicolumn{2}{|c|}{ DM1 } & \multicolumn{2}{|c|}{$\mathrm{DM} 2$} \\
\cline { 2 - 11 } & $\omega_{d}$ & $\% \delta \omega$ & $\omega_{d}$ & $\% \delta \omega$ & $\omega_{d}$ & $\% \delta \omega$ & $\omega_{d}$ & $\% \delta \omega$ & $\omega_{d}$ & $\% \delta \omega$ \\
\hline 7.29 & 7.07 & 3.02 & 6.70 & 8.09 & 6.80 & 6.72 & 6.99 & 4.12 & 6.95 & 4.66 \\
\hline 10.60 & 10.21 & 3.68 & 9.92 & 6.42 & 9.70 & 8.49 & 10.09 & 4.81 & 10.04 & 5.28 \\
\hline 13.15 & 12.79 & 2.74 & 11.77 & 10.49 & 10.78 & 18.02 & 12.71 & 3.35 & 11.96 & 9.05 \\
\hline
\end{tabular}

Table 3 Changes in frequencies caused by damage in light cases

\begin{tabular}{|c|c|c|c|c|c|c|}
\hline \multirow{2}{*}{$\begin{array}{c}\omega_{u} \\
(\mathrm{HZ})\end{array}$} & \multicolumn{6}{|c|}{ G3 (Light Damage) } \\
\cline { 2 - 7 } & $\omega_{d}$ & $\% \delta \omega$ & $\omega_{d}$ & $\% \delta \omega$ & $\omega_{d}$ & $\% \delta \omega$ \\
\hline 7.29 & 7.19 & 1.37 & 7.10 & 2.61 & 6.70 & 8.09 \\
\hline 10.60 & 10.42 & 1.70 & 10.23 & 3.49 & 10.06 & 5.09 \\
\hline 13.15 & 12.77 & 2.89 & 12.35 & 6.08 & 11.98 & 8.90 \\
\hline
\end{tabular}




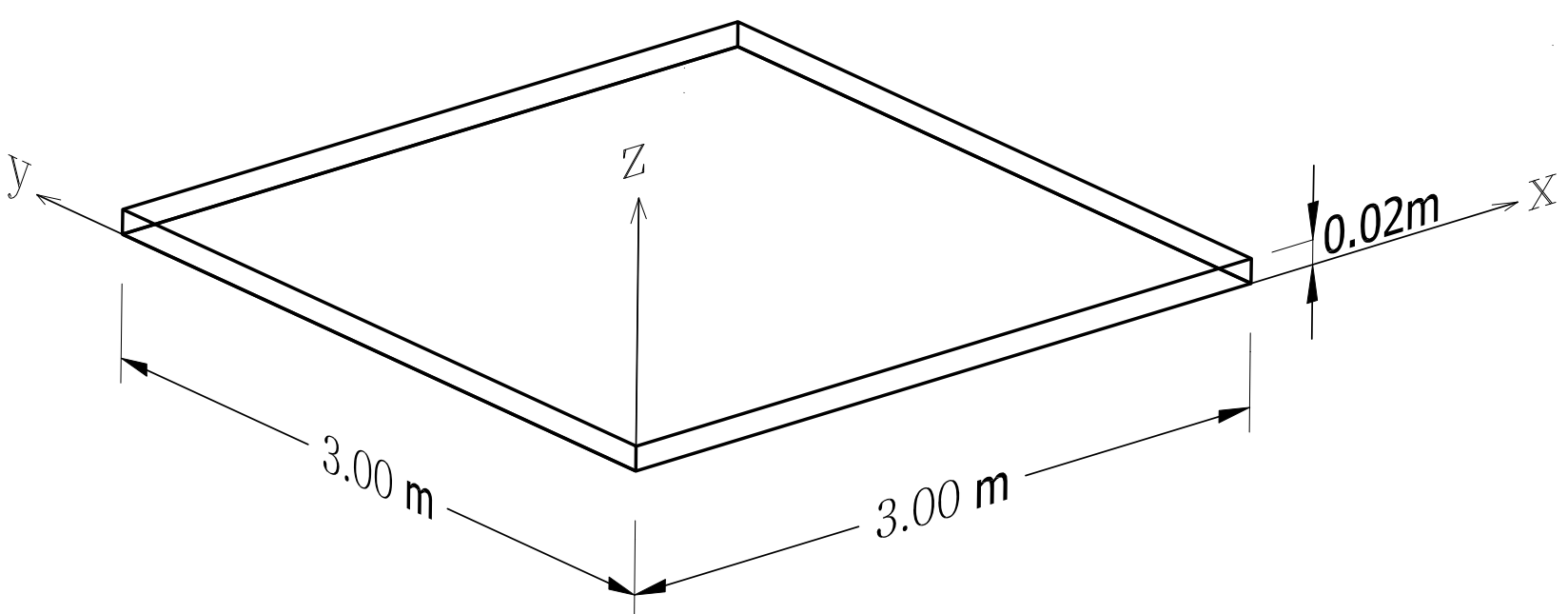

Fig.1 Geometric configuration of the steel plate

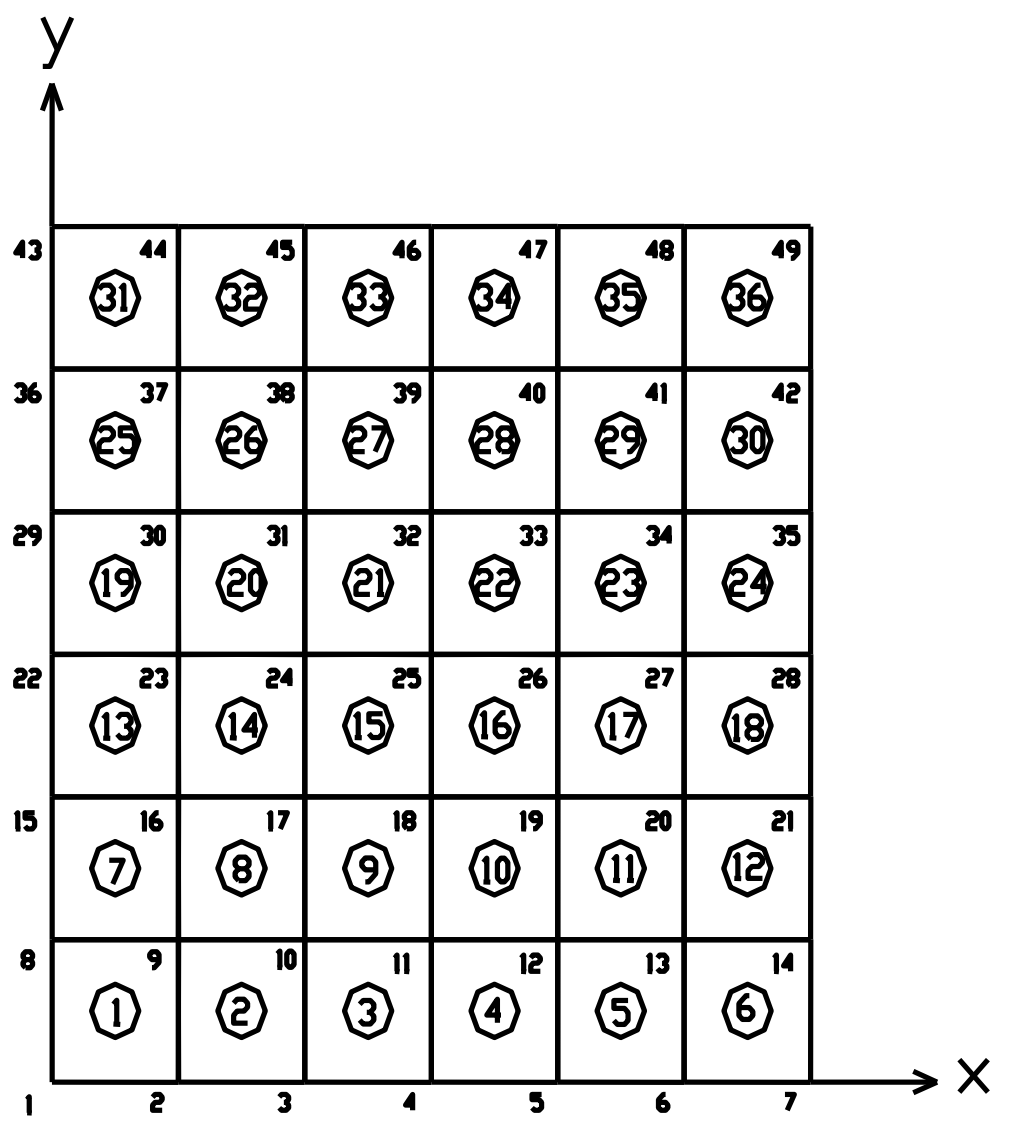

Fig.2 Finite element model of the steel plate 


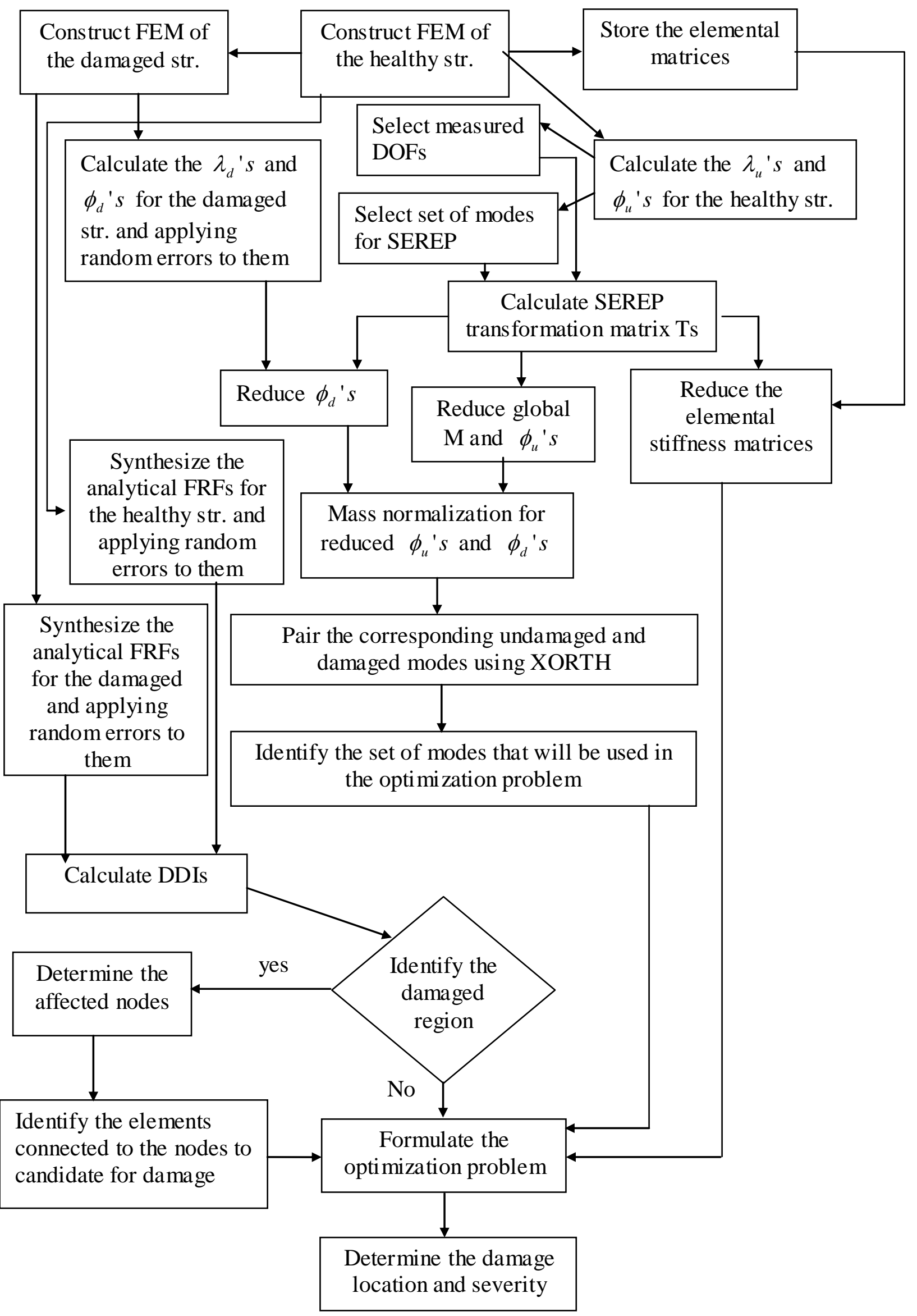

Fig. 3 Flow chart of the mathematical procedures of the combined algorithm 


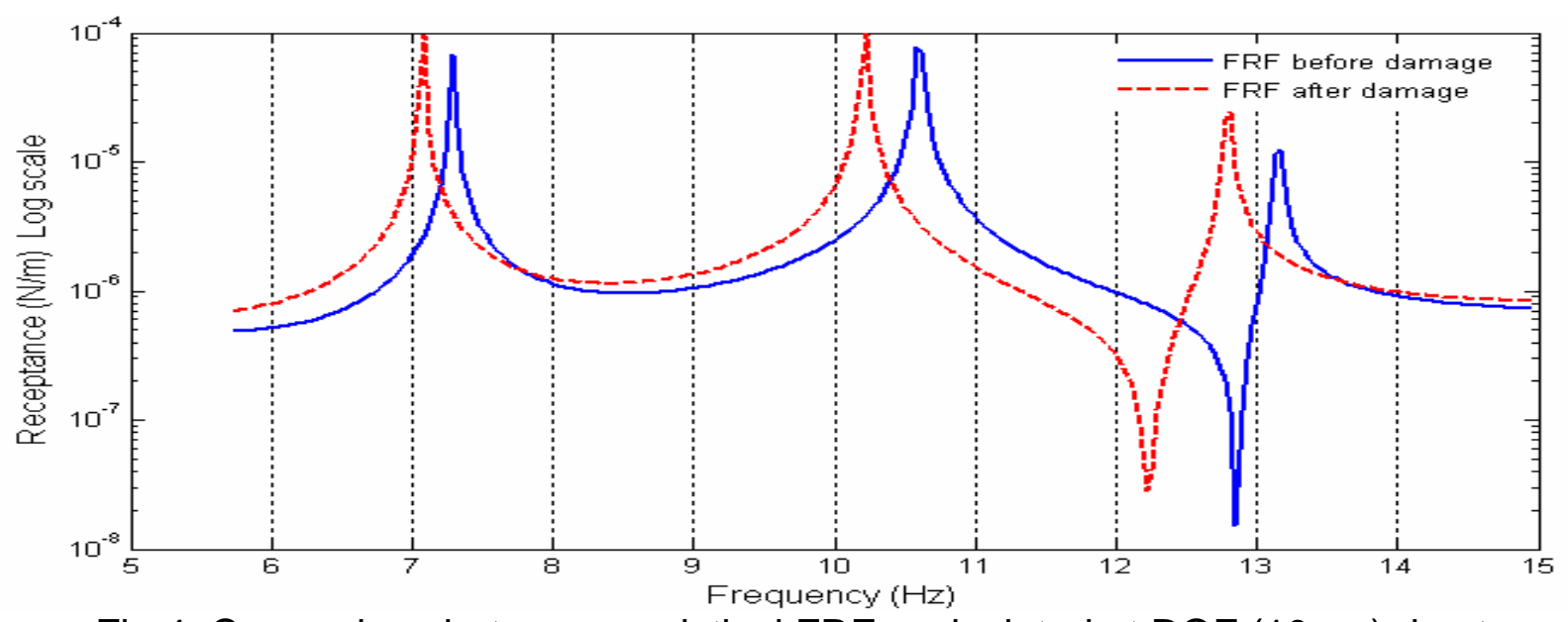

Fig.4 Comparison between analytical FRFs calculated at DOF (10-w $)$ due to excitation at DOF (34-z) for damage case DS1

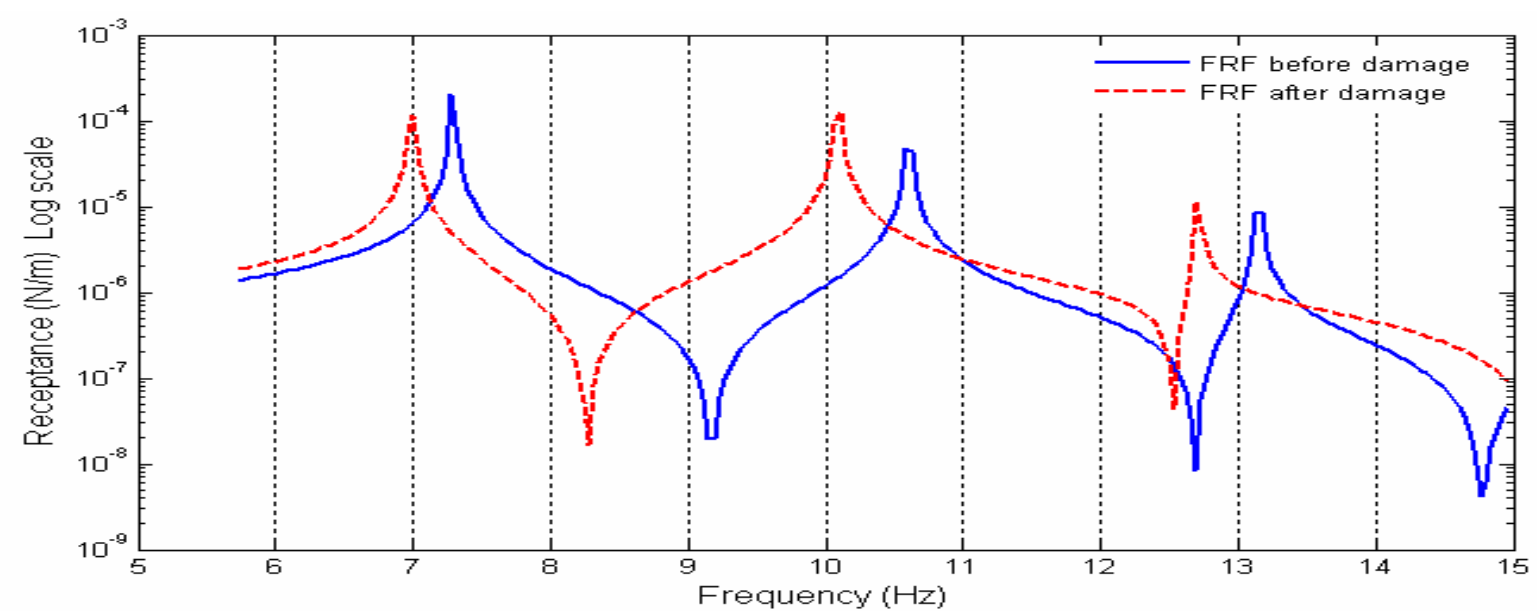

Fig.5 Comparison between analytical FRFs calculated at DOF (21-w $)$ due to excitation at DOF (34-z) for damage case DM1

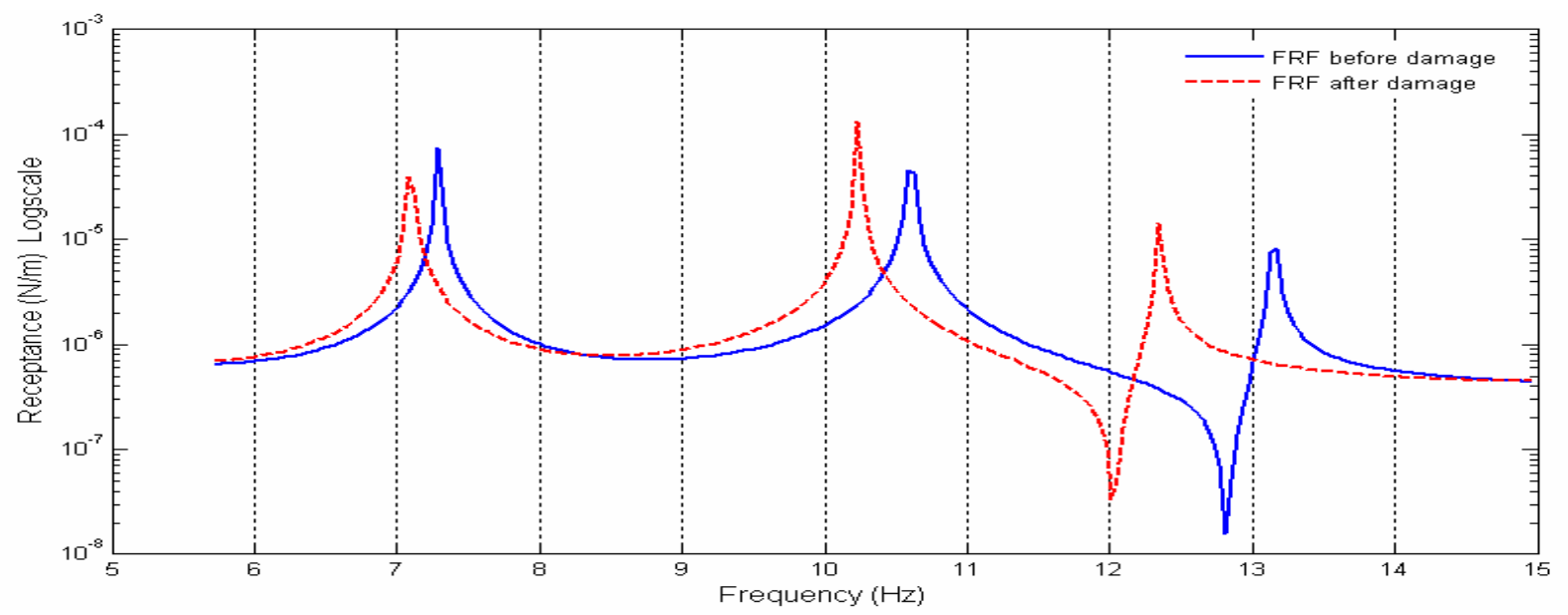

Fig.6 Comparison between analytical FRFs calculated at DOF (17-wY) due to excitation at DOF (34-z) for damage case DL2 


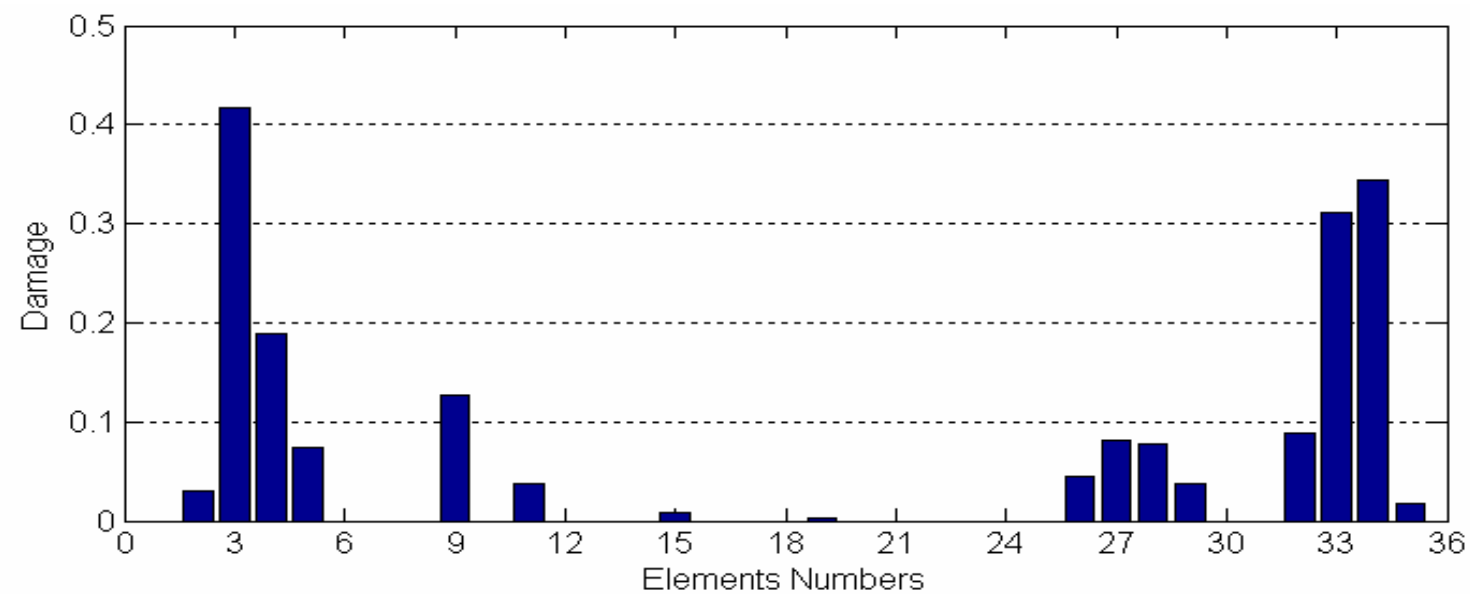

Fig. (7-a) Damage identification results for damage case DS1 using 36 elements

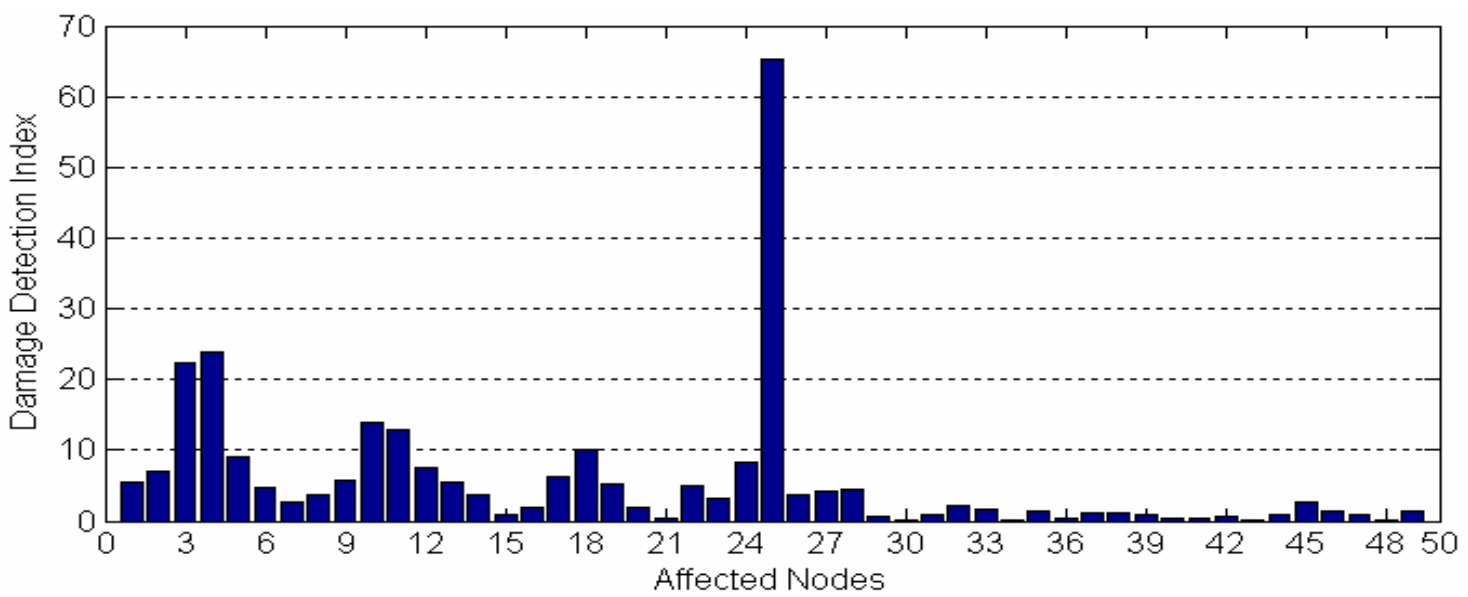

Fig. (7-b) DDI for damage case DS1 using FRFs measured at rotational DOFs about $\mathrm{x}$-axis due to excitation at DOF (34-z)

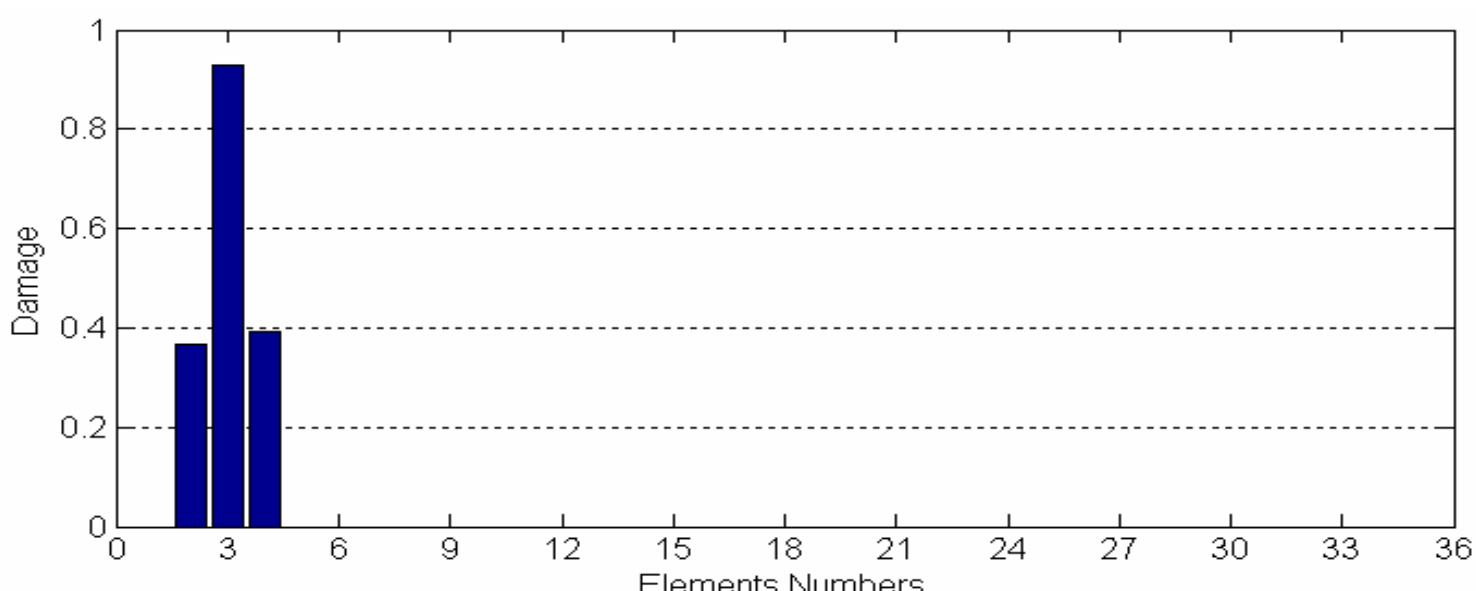

Fig. (7-c) Damage identification results for damage case DS1 based on damaged region identification using DDI 


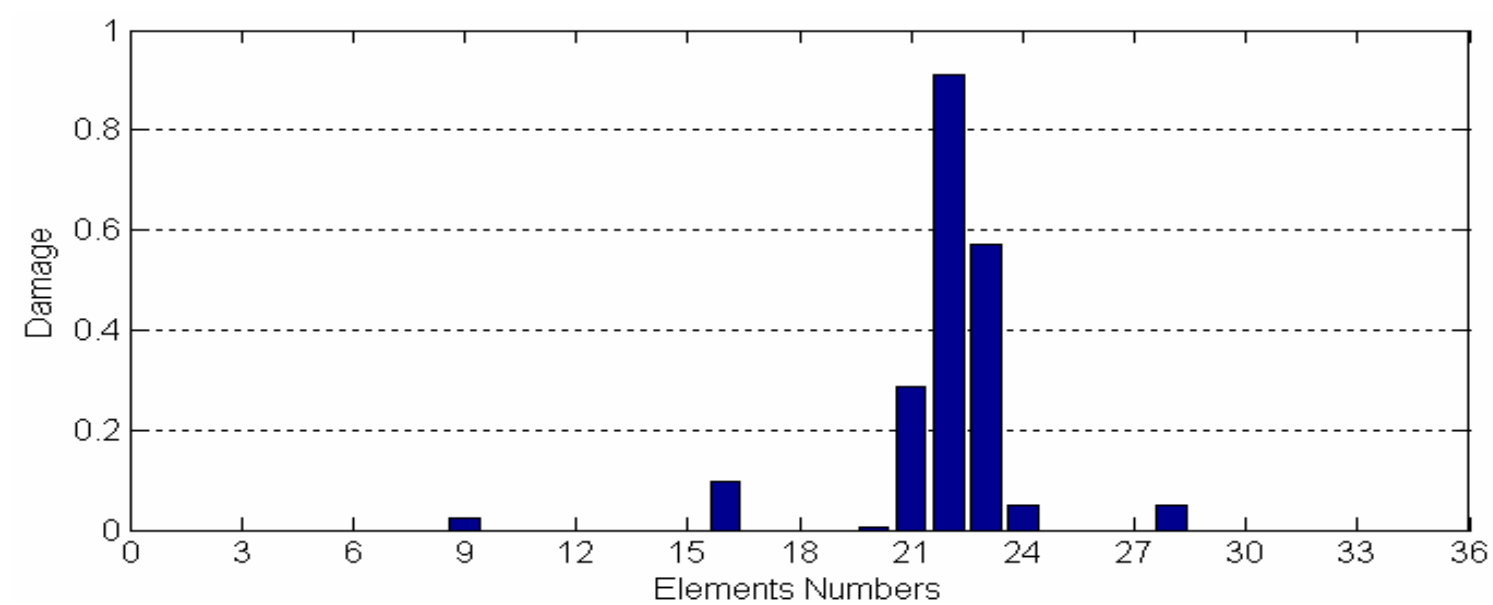

Fig. (8-a) Damage identification results for damage case DS2 using 36 elements

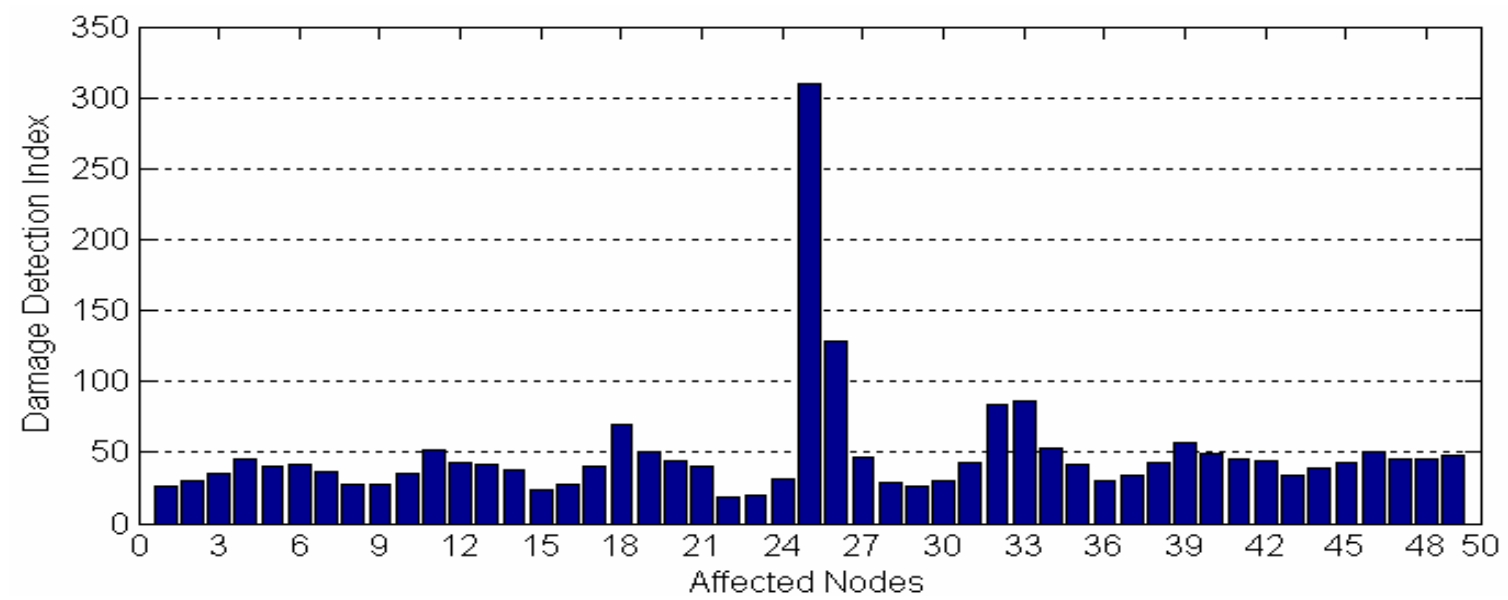

Fig. (8-b) DDI for damage case DS2 using FRFs measured at rotational DOFs about $\mathrm{x}$-axis due to excitation at DOF (34-z)

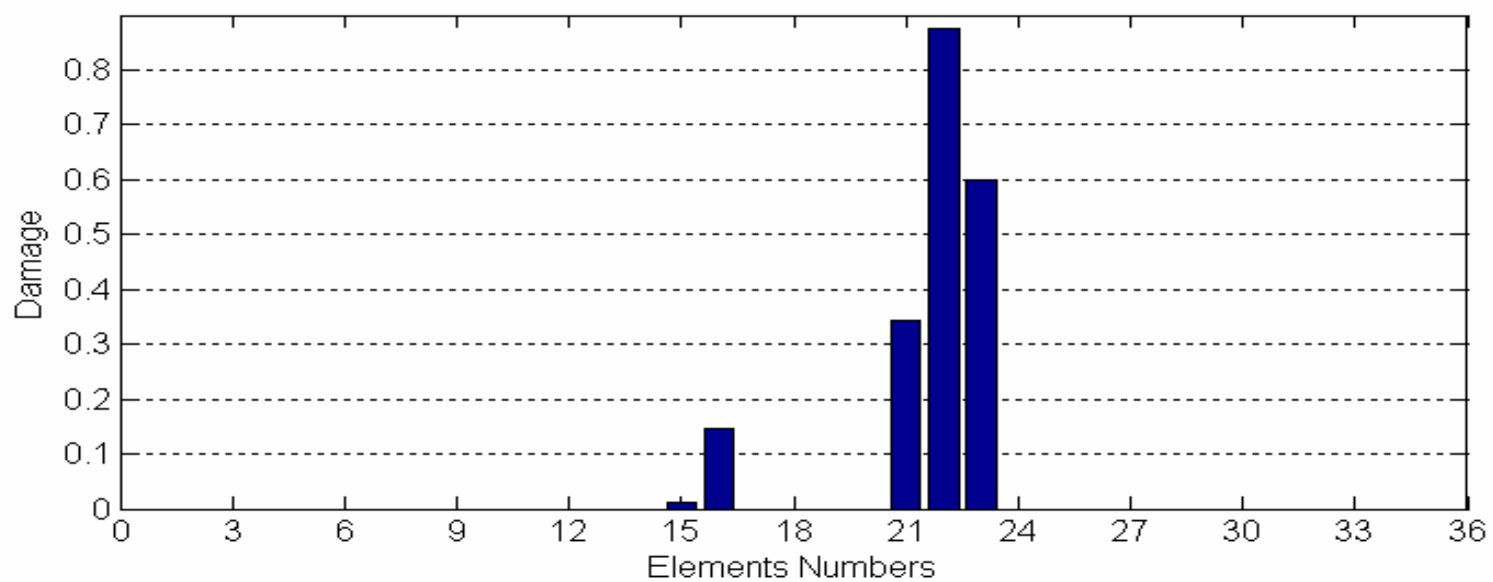

Fig. (8-c) Damage identification results for damage case DS2 based on damaged region identification using DDI 


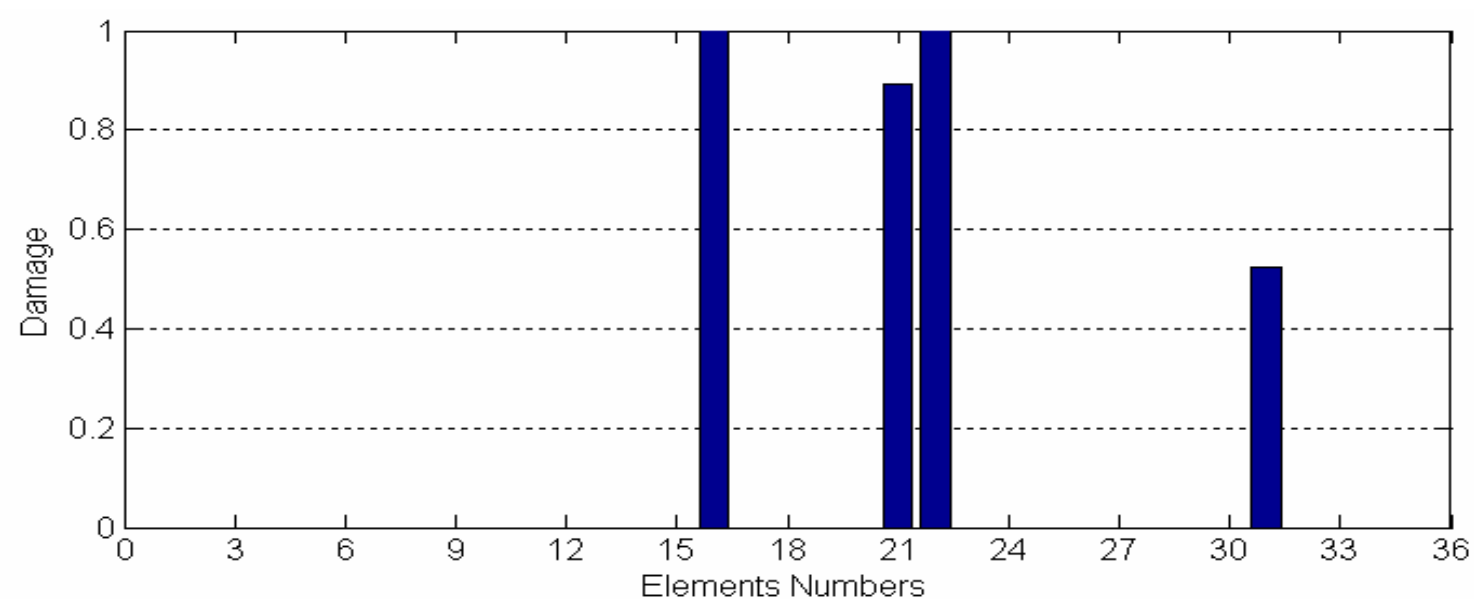

Fig. (9-a) Damage identification results for damage case DS3 using 36 elements

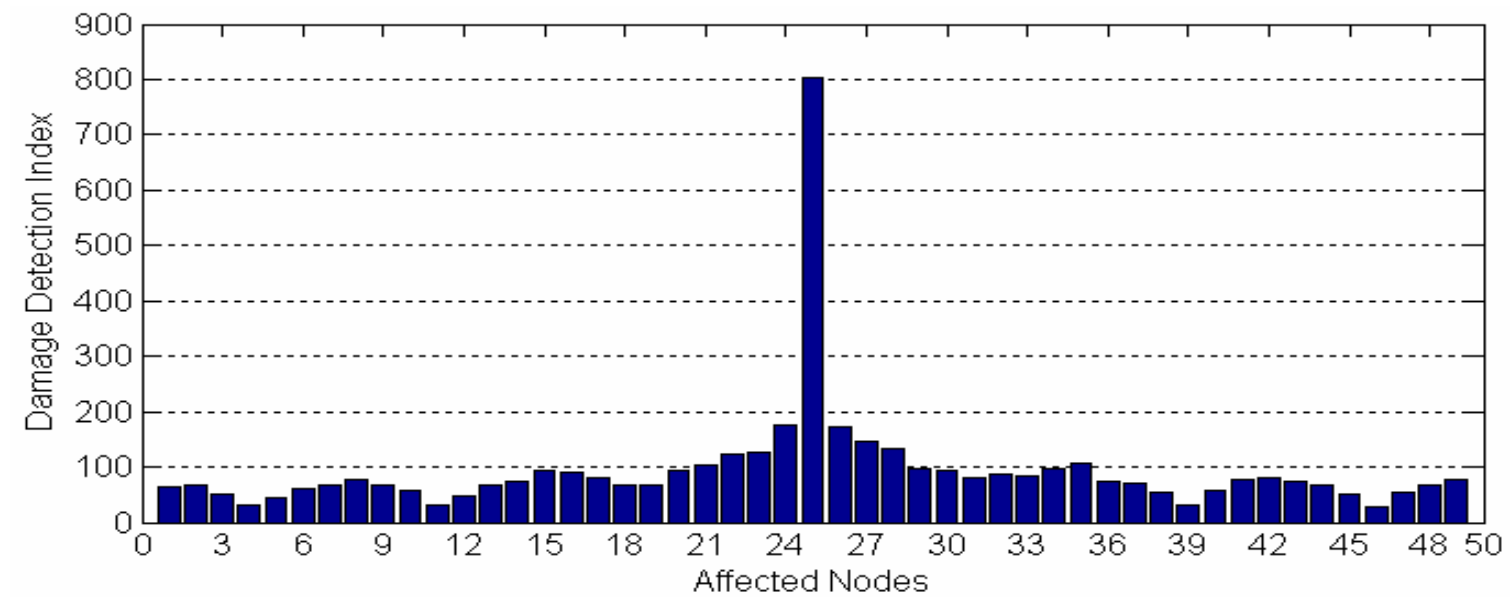

Fig. (9-b) DDI for damage case DS3 using FRFs measured at rotational DOFs about $\mathrm{x}$-axis due to excitation at DOF (34-z)

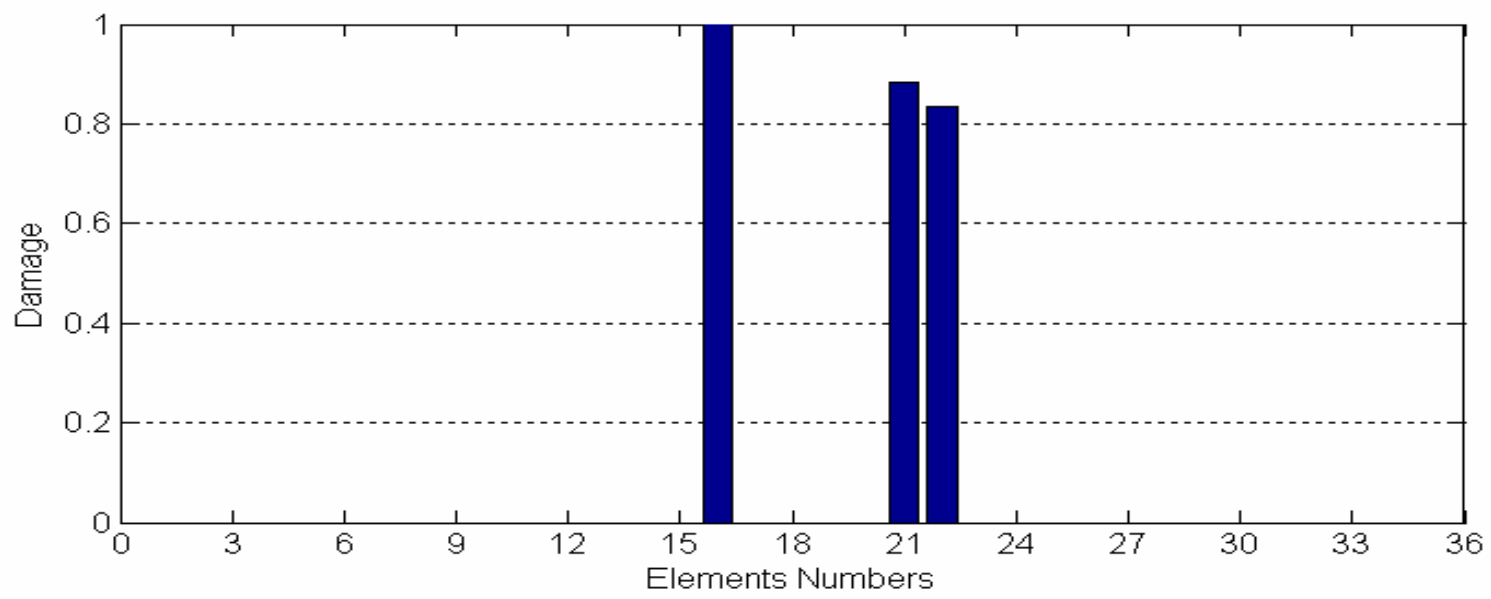

Fig. (9-c) Damage identification results for damage case DS3 based on damaged region identification using DDI 


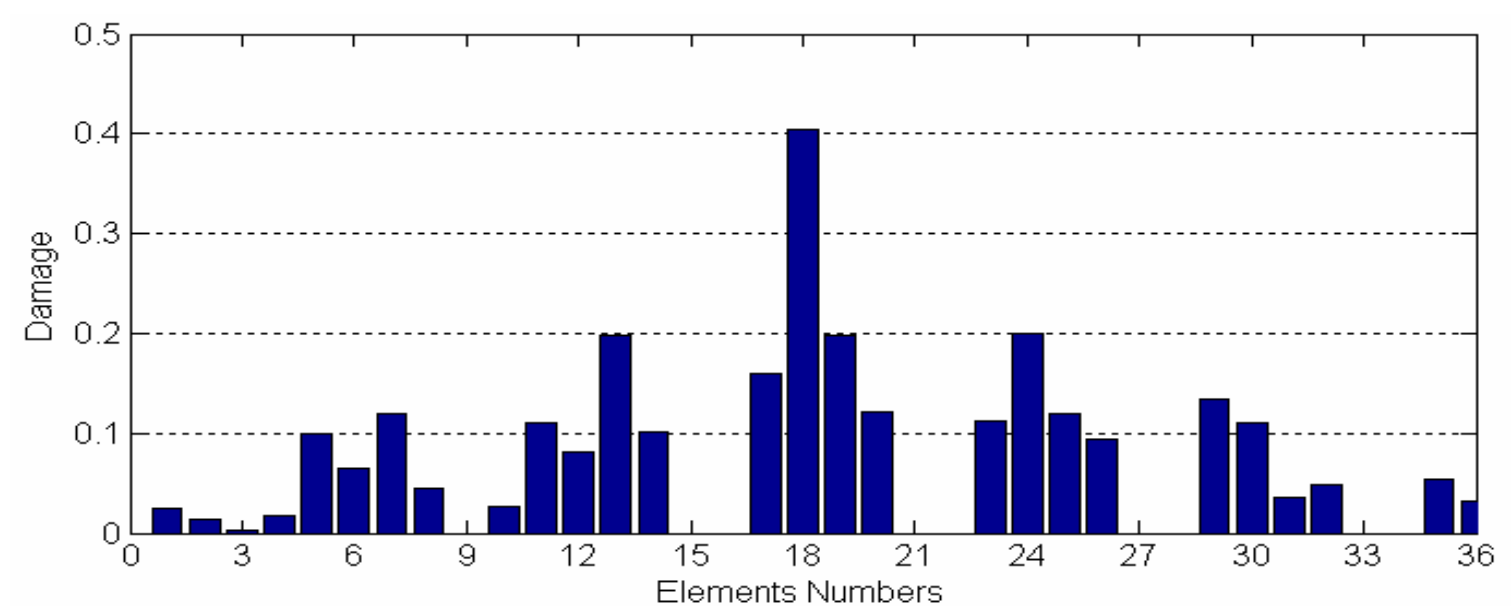

Fig. (10-a) Damage identification results for damage case DM1 using 36 elements

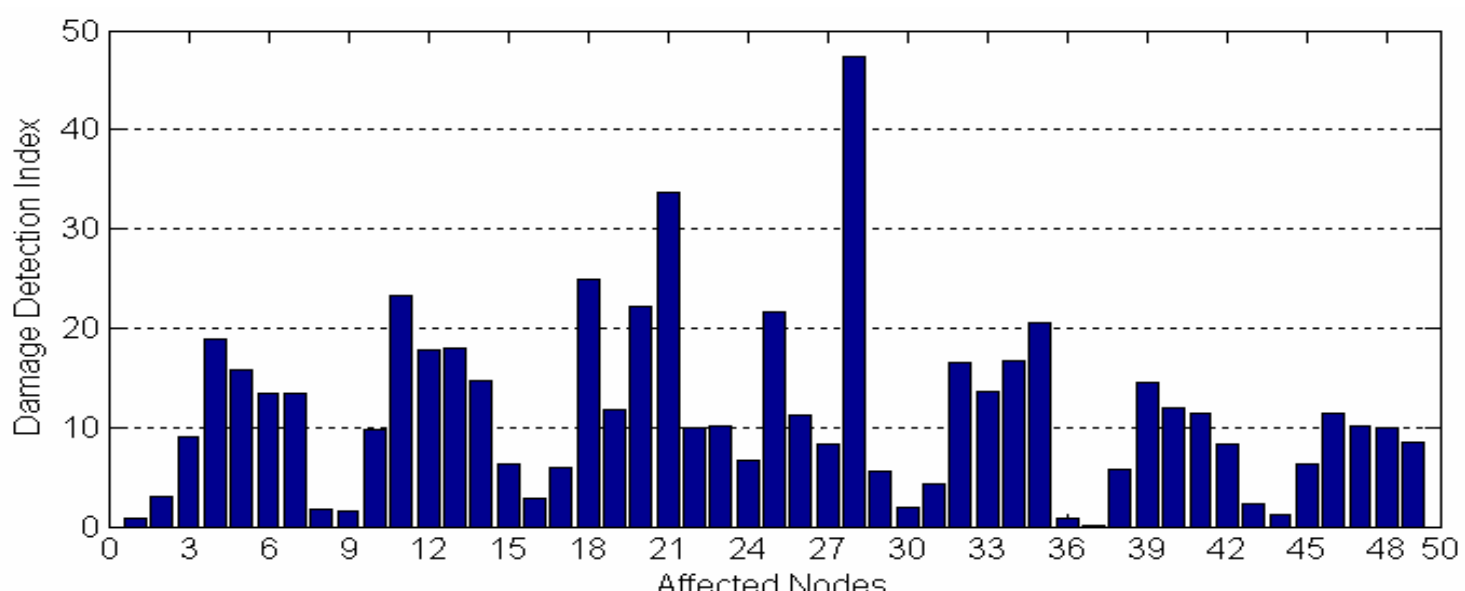

Fig. (10-b) DDI for damage case DM1 using FRFs measured at rotational DOFs about $x$-axis due to excitation at DOF (34-z)

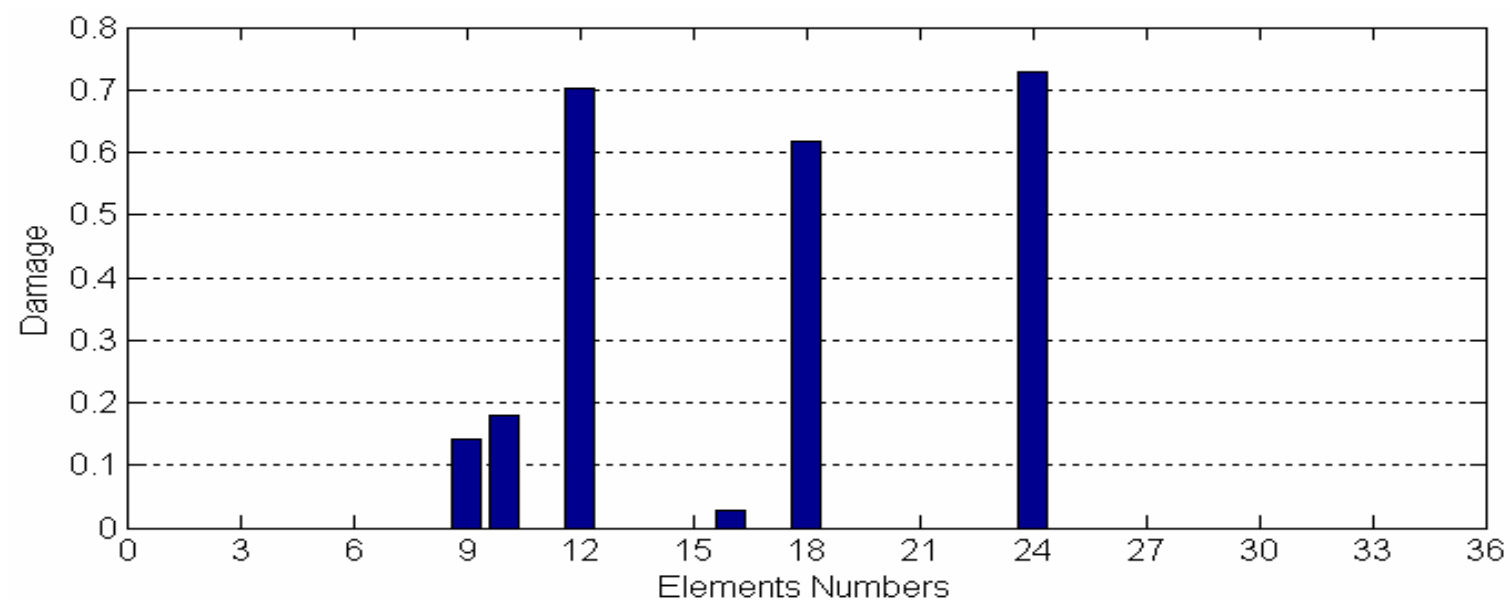

Fig. (10-c) Damage identification results for damage case DM1 based on damaged region identification using DDI 


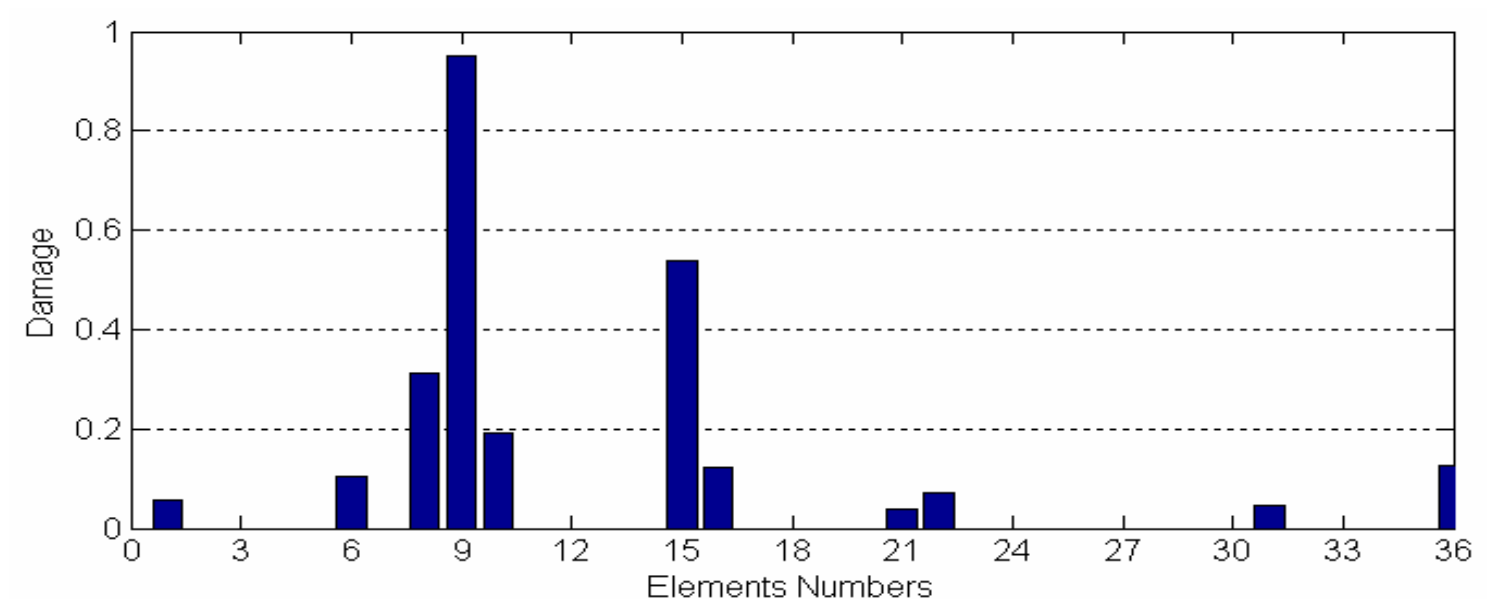

Fig. (11-a) Damage identification results for damage case DM2 using 36 elements

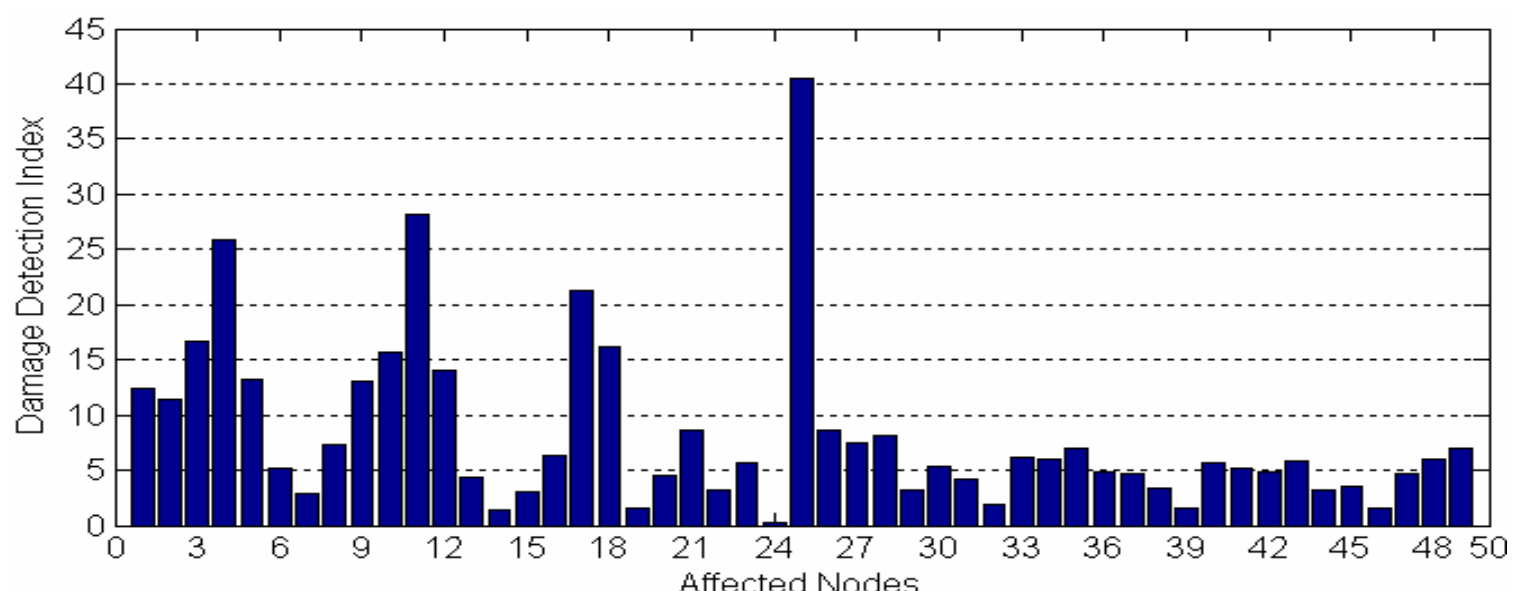

Fig. (11-b) DDI for damage case DM2 using FRFs measured at rotational DOFs about $\mathrm{x}$-axis due to excitation at DOF (34-z)

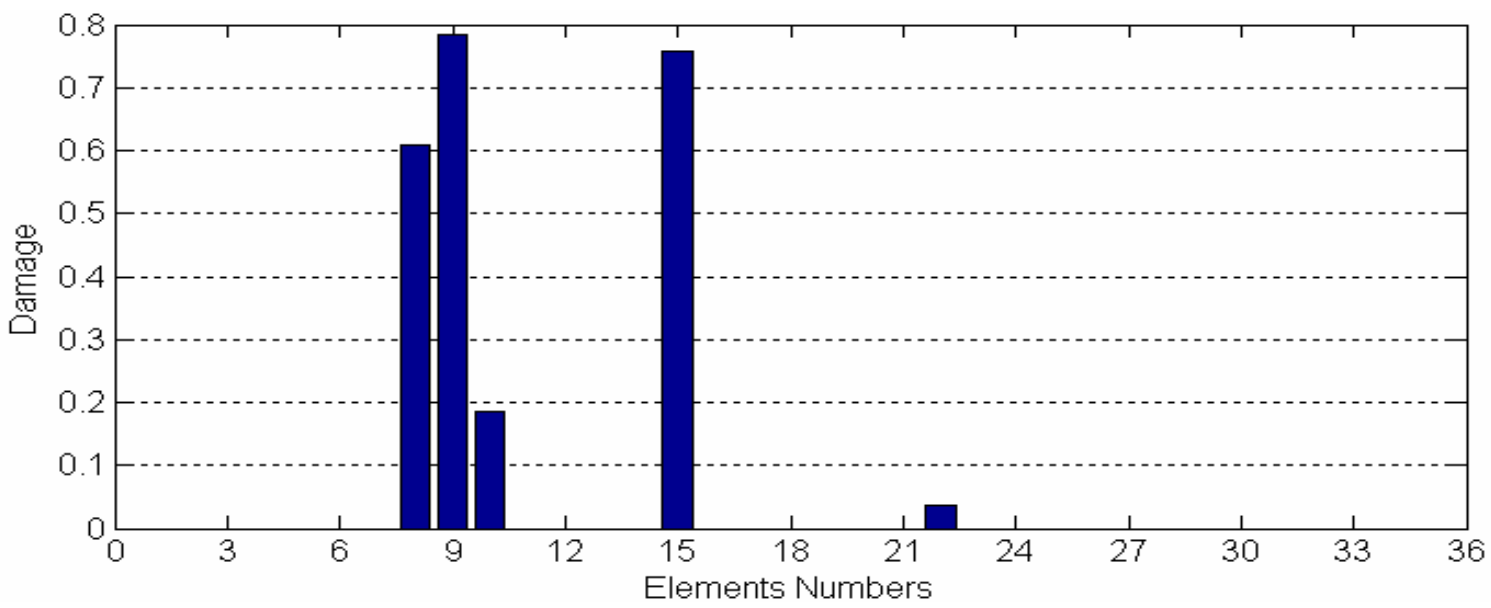

Fig. (11-c) Damage identification results for damage case DM2 based on damaged region identification using DDI 


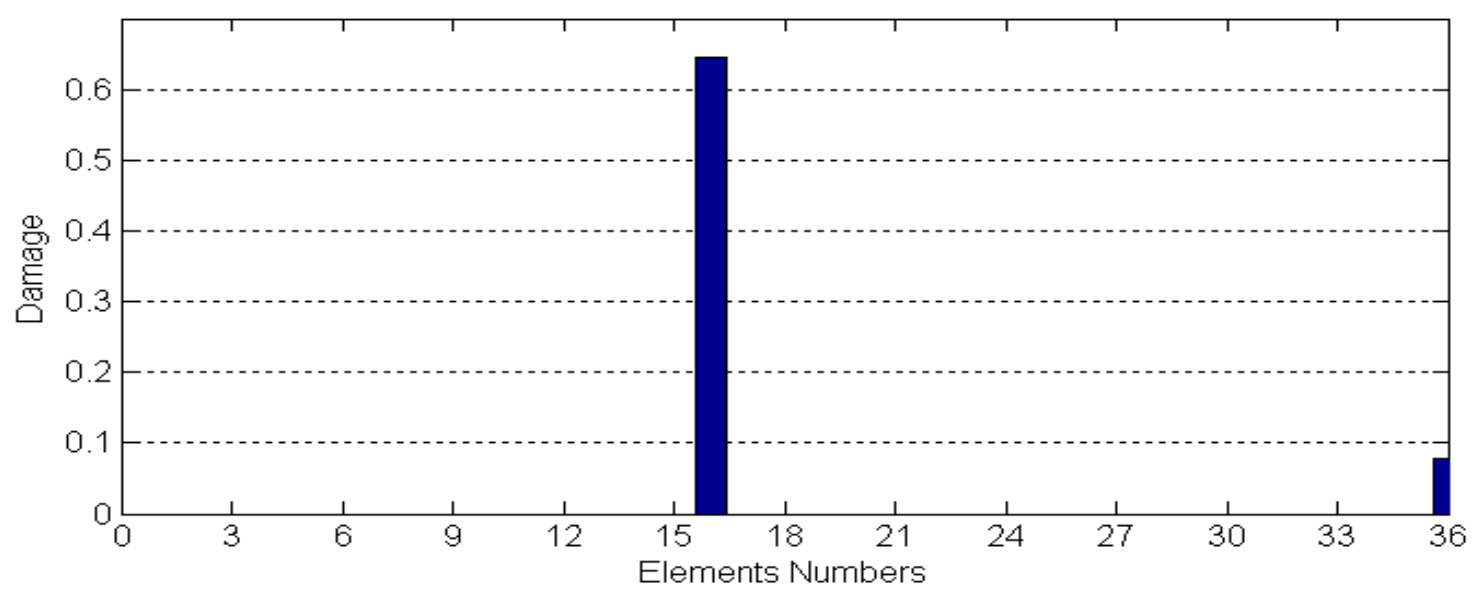

Fig. (12-a) Damage identification results for damage case DL1 using 36 elements

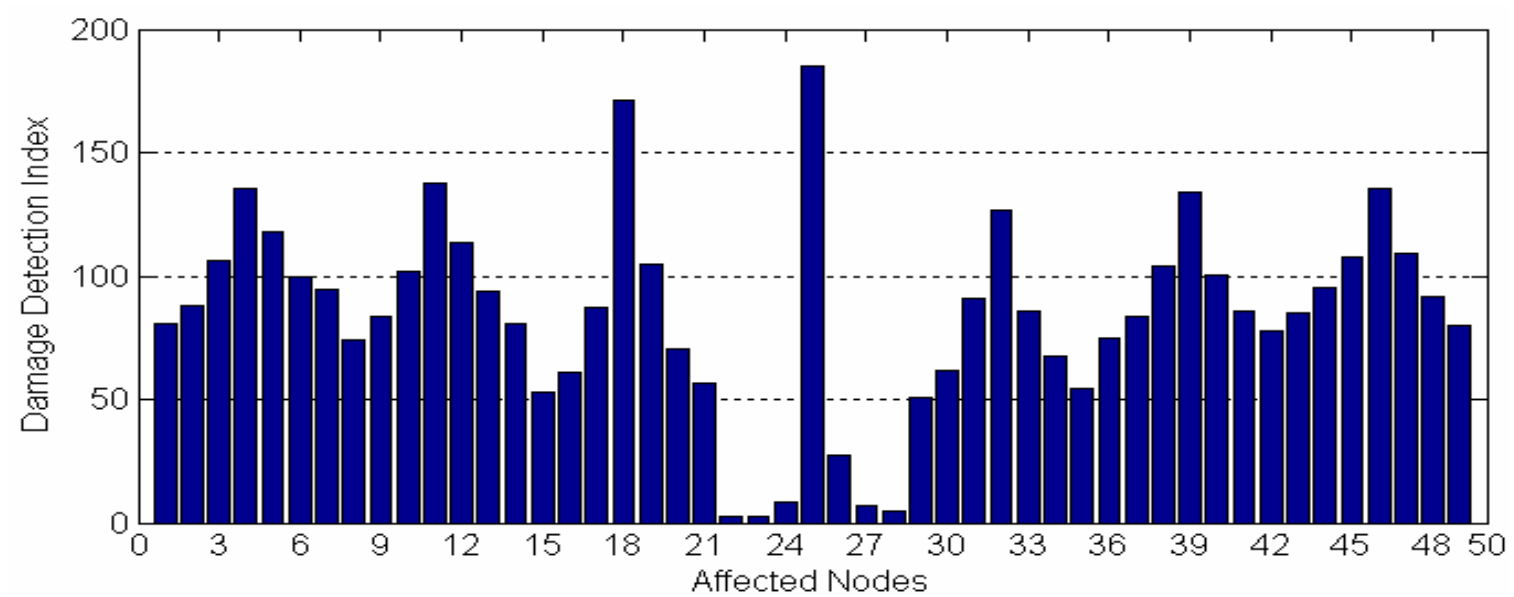

Fig. (12-b) DDI for damage case DL1 using FRFs measured at rotational DOFs about $\mathrm{x}$-axis due to excitation at DOF (34-z)

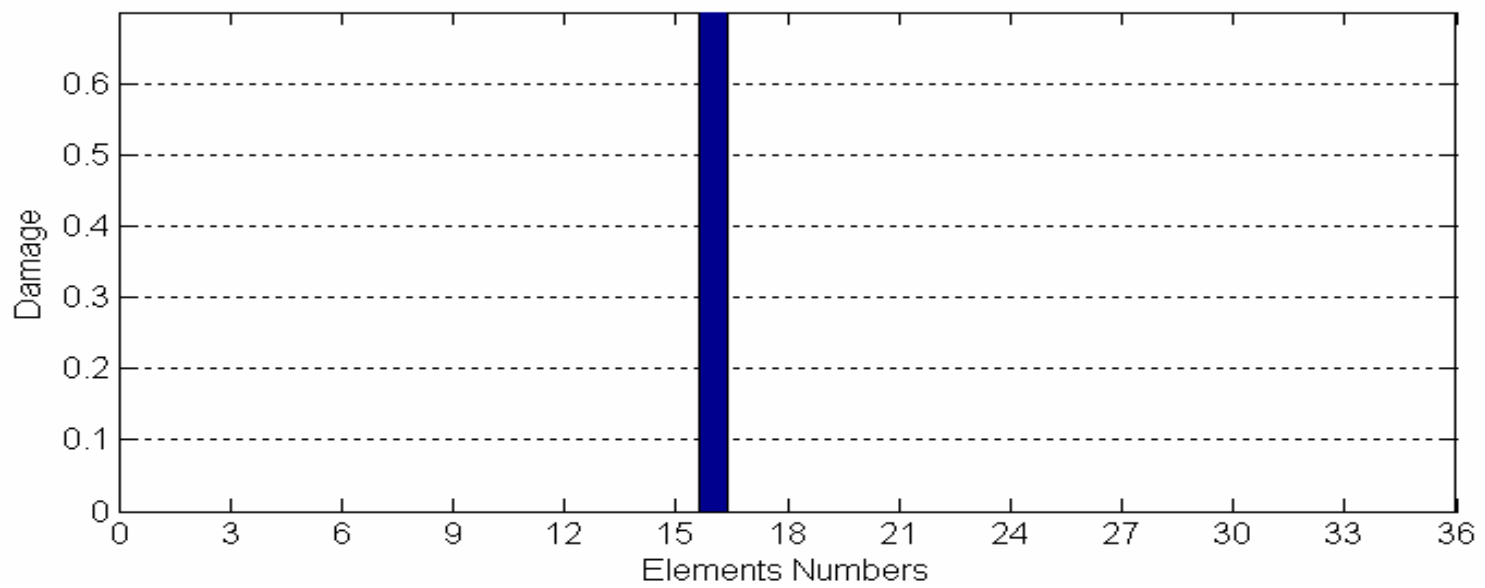

Fig. (12-c) Damage identification results for damage case DL1 based on damaged region identification using DDI 


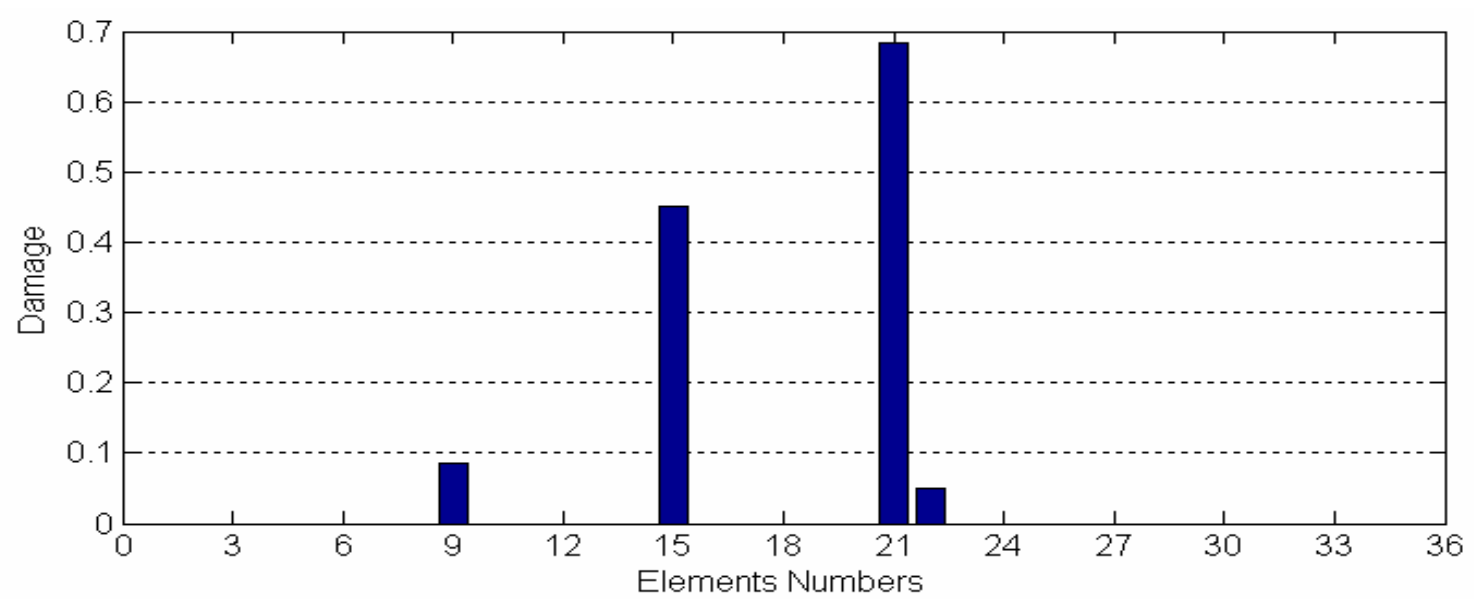

Fig. (13-a) Damage identification results for damage case DL2 using 36 elements

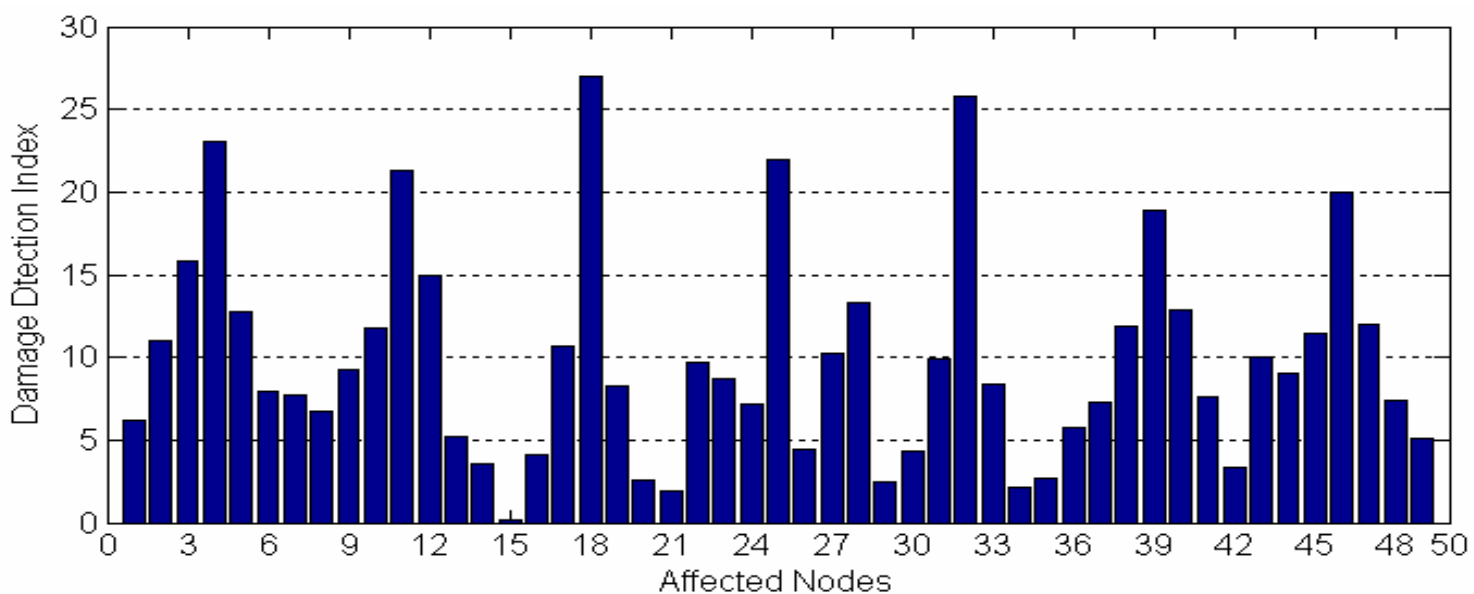

Fig. (13-b) DDI for damage case DL2 using FRFs measured at rotational DOFs about $\mathrm{x}$-axis due to excitation at DOF (34-z)

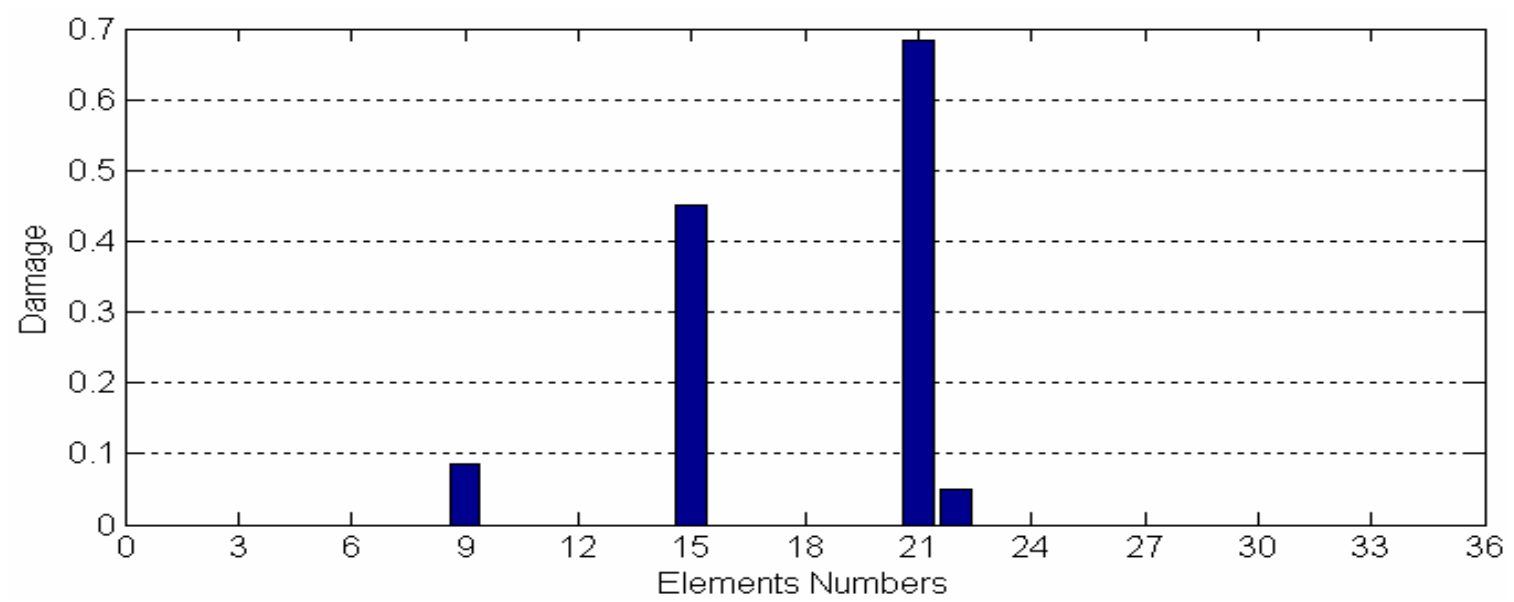

Fig. (13-c) Damage identification results for damage case DL2 based on damaged region identification using DDI 


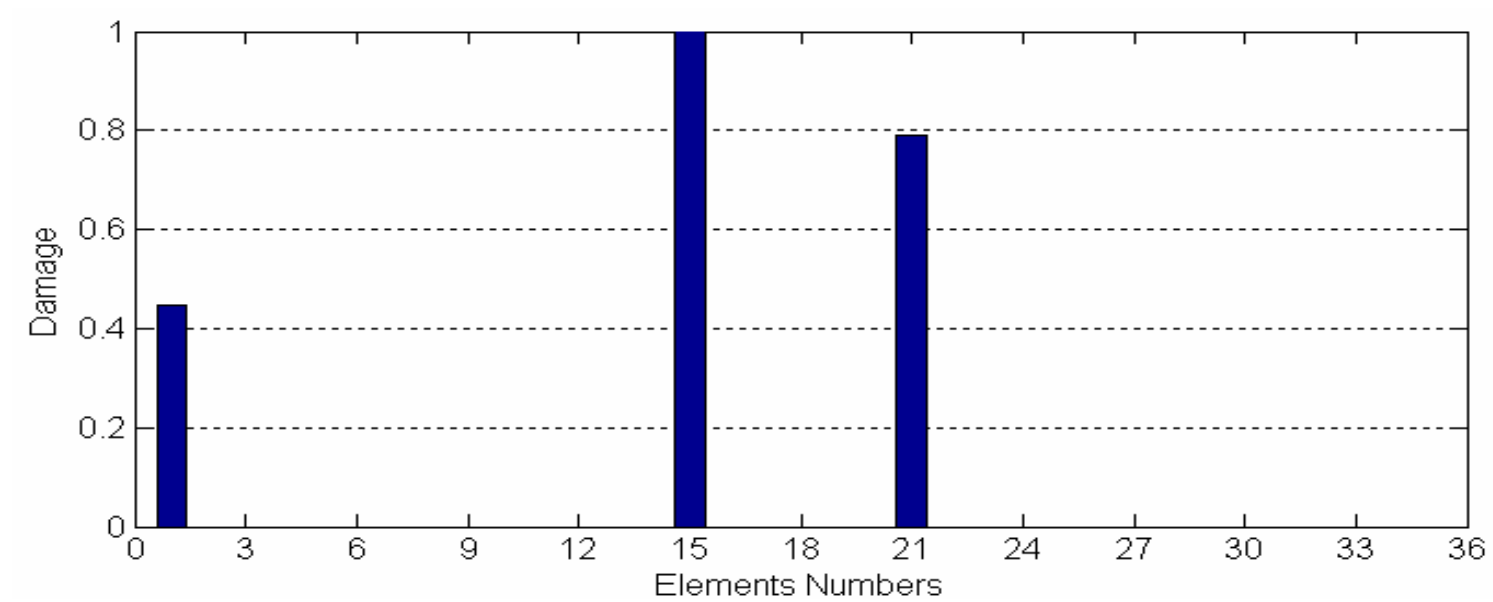

Fig. (14-a) Damage identification results for damage case DL3 using 36 elements

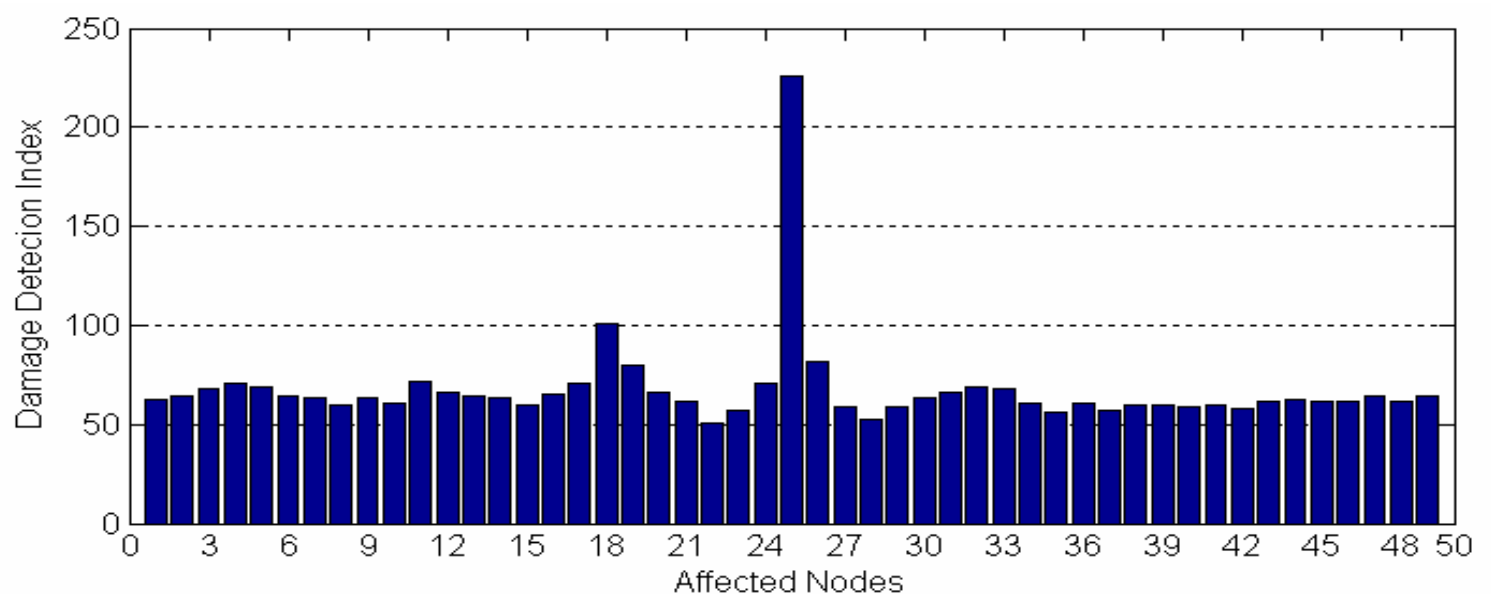

Fig. (14-b) DDI for damage case DL3 using FRFs measured at rotational DOFs about $x$-axis due to excitation at DOF (34-z)

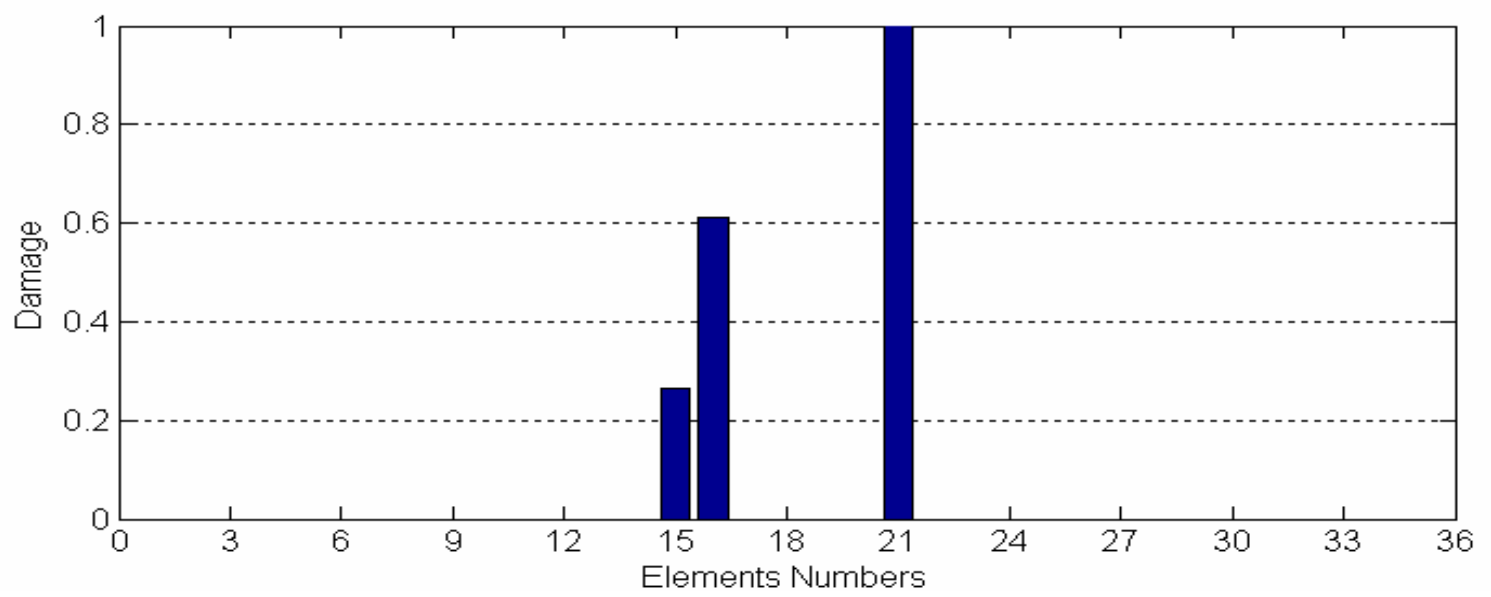

Fig. (14-c) Damage identification results for damage case DL3 based on damaged region identification using DDI 